\title{
Mammalian Target of Rapamycin Promotes Oligodendrocyte Differentiation, Initiation and Extent of CNS Myelination
}

\author{
Stacey E. Wahl, ${ }^{1}$ Lauren E. McLane, ${ }^{1}$ Kathryn K. Bercury, ${ }^{2}$ Wendy B. Macklin, ${ }^{2}$ and Teresa L. Wood ${ }^{1}$ \\ ${ }^{1}$ Department of Neurology and Neuroscience, New Jersey Medical School Cancer Center, Rutgers Biomedical and Health Sciences, Newark, New Jersey \\ 07103, and 2Department of Cell and Developmental Biology, University of Colorado School of Medicine, Aurora, Colorado 80045
}

Prior studies support a role for mammalian target of rapamycin (mTOR) signaling in oligodendrocyte differentiation and myelination. Here we use Cre-recombinase driven by the CNP promoter to generate a mouse line with oligodendrocyte-specific knockdown of mTOR (mTOR cKO) in the CNS. We provide evidence that mTOR is necessary for proper oligodendrocyte differentiation and myelination in the spinal cord. Specifically, the number of mature oligodendrocytes was reduced, and the initiation and extent of myelination were impaired during spinal cord development. Consistent with these data, myelin protein expression, including myelin basic protein, proteolipid protein, myelin oligodendrocyte glycoprotein, and myelin-associated glycoprotein, was delayed in the spinal cord. Hypomyelination of the spinal cord persisted into adulthood, as did the reduction in numbers of mature oligodendrocytes. In the cortex, the structure of myelin appeared normal during development and in the adult; however, myelin protein expression was delayed during development and was abnormal in the adult. Myelin basic protein was significantly reduced in all regions at postnatal day 25 . These data demonstrate that mTOR promotes oligodendrocyte differentiation and CNS myelination in vivo and show that the requirement for mTOR varies by region with the spinal cord most dependent on mTOR.

Key words: differentiation; mTOR; myelination; oligodendrocyte; signaling

\section{Introduction}

In contrast to the peripheral nervous system where myelination is regulated predominantly by neuregulin, multiple signaling receptors have demonstrated cell-autonomous roles in promoting oligodendrocyte differentiation and/or developmental myelination in the CNS, including insulin-like growth factor type 1 receptor (Ye et al., 2002; Zeger et al., 2007), fibroblast growth factor receptors-1/2 (Furusho et al., 2012), and TrkB (Wong et al., 2013). Downstream of these receptors, the coordinated actions of signaling pathways converge on transcriptional regulators to orchestrate differentiation of the oligodendrocyte progenitor cells (OPCs) and proper axonal myelination. Identifying the precise pathways that regulate the myelination process is important for the treatment of neuropathologies, such as multiple sclerosis. In multiple sclerosis, failure of oligodendrocyte progenitor cells to

Received 0ct. 7, 2013; revised Feb. 3, 2014; accepted Feb. 8, 2014.

Author contributions: S.E.W. designed research; S.E.W., L.E.M., and K.K.B. performed research; S.E.W., L.E.M., W.B.M., and T.L.W. analyzed data; S.E.W., L.E.M., and T.L.W. wrote the paper.

This work was supported by National Multiple Sclerosis Society Grant RG4015 to T.L.W., National Institute of Neurological Disorders \& Stroke Grant NS082203 to W.B.M. and T.L.W., and National Research Service Award NS076187 to S.E.W. We thank Dr. Christopher Lynch, Penn State College of Medicine for providing the mTOR ${ }^{\text {tm1.1Clyn }}$ floxed mice; Dr. Klaus Nave for permission to use the CNP-Cre mouse line; Dr. Holly Colognato for providing the CNP-Cre mice; Corey Goyeneche for technical assistance; Dorothy Dill and Hilary Sachs for assistance with EM; and Jared Ahrendsen for helpful discussions.

The authors declare no competing financial interests.

Correspondence should be addressed to Dr. Teresa L. Wood, Department of Neurology \& Neuroscience and Cancer Center H1200, New Jersey Medical School/Rutgers Biomedical \& Health Sciences, 205 S. Orange Avenue, Newark, NJ 07101-1709. E-mail: woodte@njms.rutgers.edu.

DOI:10.1523/JNEUROSCI.4311-13.2014

Copyright $\odot 2014$ the authors $\quad 0270-6474 / 14 / 344453-13 \$ 15.00 / 0$ differentiate and produce new myelin within a demyelinated lesion can reduce myelin repair over time (Franklin, 2002).

Several investigators have identified the PI3K/Akt pathway as a major regulator of developmental myelination (Flores et al., 2008; Goebbels et al., 2010; Harrington et al., 2010). A major downstream mediator of PI3K/Akt, the mammalian target of rapamycin (mTOR), has also been implicated in oligodendrocyte differentiation in vitro and in developmental myelination (Narayanan et al., 2009; Tyler et al., 2009, 2011; Guardiola-Diaz et al., 2012). Our initial studies showed that mTOR inhibition of OPCs in vitro blocked the transition from the OPC to the immature oligodendrocyte and decreased cellular morphological complexity, myelin protein expression, and myelination in coculture with DRG axons (Tyler et al., 2009). We further defined the mTOR-regulated proteome in differentiating oligodendrocytes and determined that mTOR has significant effects in oligodendrocytes on lipid synthesis, transcription factor regulation, and the cytoskeleton (Tyler et al., 2011), processes that are integral to oligodendrocyte development (for recent review, see Wood et al., 2013).

Recent studies have begun to elucidate the function of signaling pathways in developmental myelination in vivo. The W.B.M. laboratory initially showed that a constitutively active form of Akt, expressed in oligodendroglia, causes early and enhanced myelination that is mTOR dependent (Narayanan et al., 2009). Loss of Erk1/2 in oligodendroglia in vivo revealed essential functions for this pathway in regulating the extent of myelination and myelin maintenance, with no effect on oligodendrocyte differentiation or the onset of myelination (Guardiola-Diaz et al., 2012; Ishii et al., 2012). Recently, Sherman et al. (2012) demonstrated that a lack 
of mTOR in Schwann cells results in reduced peripheral myelination, nerve conduction velocity, and overall nerve fiber diameter, independent of an effect on Schwann cell differentiation.

The goal of these studies was to determine the function of mTOR in CNS myelination through oligodendrocyte lineagespecific deletion of mTOR. We show that the onset of myelination as well as myelin thickness are impaired in the mTOR cKO spinal cord. We further show that the differentiation of OPCs is reduced during development and in the adult spinal cord. Interestingly, we observed significant regional diversity of mTOR function in the CNS and propose that the role of mTOR in CNS myelination varies in the brain and spinal cord.

\section{Materials and Methods}

Materials. Antibodies for phosphorylated (\#4858) and total (\#2217) forms of ribosomal protein S6, phosphorylated (\#4060), and total (\#4691) Akt, as well as total mTOR (\#2972) were purchased from Cell Signaling Technology. Cell signaling antibodies were used at 1:1000 for Western blot analysis. Olig2 antibodies were purchased from Millipore (AB9610, 1:250 for immunohistochemistry [IHC]). Antibodies for myelin oligodendrocyte glycoprotein (MOG) (ab32760, 1:500 for Western blot) and myelin-associated glycoprotein (MAG) (ab89780, 1:1000 for Western blot) were purchased from Abcam. Myelin basic protein (MBP) antibodies from Covance were used (SMI-99, 1:2000). Proteolipid protein (PLP) and DM20 were detected using the AA3 hybridoma antibody, a gift from W.B.M. The PDGFR $\propto$ antibody was purchased from BD Biosciences PharMingen (\#558774, 1:50 for IHC), and the CC1 (adenomatous polyposis coli) antibody was purchased from Calbiochem (OP80, 1:100 for IHC). An antibody to GFP was purchased from Aves Laboratories (GFP-1020, 1:500 for IHC). Ki67 antibodies were purchased from Vector Laboratories (VPK451, 1:500 for IHC). DAPI was purchased from Invitrogen (D1306, 1:5000 for IHC). Additional reagents for staining and processing tissue (chloroform, Triton X-100, phenol/chloroform, and TRIzol) were purchased from Sigma and TissueTek (OCT). Ketamine and xylazine were purchased from Bioniche Pharma and Lloyd, respectively. Cytoseal XYL was purchased from Thermo Scientific.

Animal care and breeding. All mouse protocols were conducted in accordance with the guidelines set forth by Rutgers University and the National Institutes of Health. Mice were housed in a barrier facility with a 12/12 light/dark cycle. Mice carrying a floxed-mTOR allele $\left(\right.$ Mtor $^{\text {tm1.1Clyn }}$ ) were obtained from Dr. Christopher Lynch (Pennsylvania State College of Medicine, Hershey, PA) (Lang et al., 2010a, b; Carr et al., 2012). The floxed-mTOR mice were bred with a dual-reporter mouse

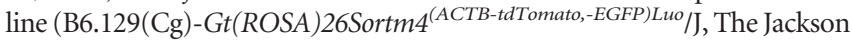
Laboratory). These mice contain the $m \operatorname{Tm} G$ reporter, which globally expresses tomato red, and, in cells with active Cre recombise, express GFP. CNP-Cre mice were obtained from K. Nave (Lappe-Siefke et al., 2003). All strains were on a C57/Bl/6 background. Mice homozygous for $m T O R$ floxed- and $m T / m G$ reporter alleles and heterozygous for CNPCre were used for breeding to generate $\mathrm{Cre}^{+}$or $\mathrm{Cre}^{-}$littermates for experiments. The resultant $m T O R^{f l f l}$ mice expressing Cre $\left(\mathrm{Cre}^{+/-}\right)$are hereafter referred to as mTOR cKO with $m \mathrm{mOR}^{\mathrm{fl} / \mathrm{fl}} / \mathrm{Cre}^{-/-}$littermates used as controls. Both males and females were used in all analyses.

Tissue preparation and immunofluorescence. Tissues were perfused or drop-fixed depending on age. For animals postnatal day (PND) 14 and younger, animals were rapidly decapitated, brains and spinal cords were removed and stored in 3\% PFA overnight. Tissue was then changed to $30 \%$ sucrose for dehydration. Once dehydrated, tissues were blocked and frozen in OCT on dry ice/ethanol and stored at $-80^{\circ} \mathrm{C}$. For animals P25 and older, animals were deeply anesthetized with a 6:1 ketamine:xylazine mixture. A transcardial perfusion was performed first with RPMI containing $50 \mathrm{U} / 1 \mathrm{~L}$ heparin (Hospira) and then 3\% PFA for $5 \mathrm{~min}$. The brains and spinal cords were removed and stored in 3\% PFA overnight. Tissue was then dehydrated and frozen as for younger tissues.

For immunofluorescence, $12 \mu \mathrm{m}$ cryosections were mounted and frozen at $-80^{\circ} \mathrm{C}$ before use. Slides were thawed for $10 \mathrm{~min}$, washed in TBS, and incubated in $50 \mathrm{~mm}$ ammonium chloride for $30 \mathrm{~min}$ at room tem- perature. For CC1 staining, antigen retrieval was performed before permeabilization. Slides were microwaved $3 \times 40 \mathrm{~s}$ in $10 \mathrm{~mm}$ sodium chloride on medium power, with $25 \mathrm{~min}$ in between microwaving. Sections were permeabilized in $10 \%$ Triton X-100/2\% goat serum for $30 \mathrm{~min}$ at room temperature. Sections were then incubated in TGB superblock for $1 \mathrm{~h}$ at room temperature. Primary antibody was added to TGB diluent and incubated overnight at $4^{\circ} \mathrm{C}$ in a humid chamber. Primary antibodies included Olig2, adenomatous polyposis coli (CC1), PDGFR $\alpha$, and GFP used at conditions described above. After primary incubation, slides were washed in $0.05 \%$ Triton X-100 in TBS (T-Buffer) $3 \times 10$ min followed by a single $5 \mathrm{~min}$ wash in TBS. Sections were then incubated in AlexaFluor secondary antibodies (Invitrogen, $1: 750$ ) for $2 \mathrm{~h}$ at $37^{\circ} \mathrm{C}$ in a humid chamber. Slides were once again washed $3 \times 10 \mathrm{~min}$ in T-Buffer and $1 \times$ $5 \mathrm{~min}$ in TBS. For DAPI staining, sections were incubated with DAPI for $15 \mathrm{~min}$, and then slides were washed again $2 \times 5 \mathrm{~min}$ in TBS. Slides were then coverslipped with Fluorogel (EMS).

Lineage cell counts. At least five animals per genotype were used to examine lineage marker expression for PND14. Three animals per genotype were used to examine lineage marker expression at 8 weeks. In the spinal cord, cells were counted on three or more nonadjacent rostral sections and three or more nonadjacent caudal sections totaling a minimum of six sections counted per animal. The $20 \times$ pictures were taken of the dorsal and ventral white matter. In the brain, three or more nonadjacent sections were counted per animal, and $20 \times$ pictures were taken of the medial, mediolateral, and lateral corpus callosum. Counts were statistically compared using Student's $t$ test.

Protein isolation and Western blot analysis. Mice were rapidly decapitated, and the tissue of interest was removed. Mice that were older than PND14 were deeply anesthetized with a 3:1 ketamine/xyline mixture before decapitation. The brain was dissected into cortical, subcortical, and cerebellar regions. All tissues were immediately frozen in dry ice/ ethanol and stored at $-80^{\circ} \mathrm{C}$. To isolate protein, tissue was homogenized in $500 \mu$ l of lysis buffer. Lysis buffer contains 10 mM HEPES, pH 8.0, 150 $\mathrm{mm} \mathrm{NaCl}, 0.02 \%$ sodium azide, $0.1 \%$ SDS, $1 \%$ NP40 (IgepalCA 630 Sigma), 0.5\% deoxycholic acid, $50 \mathrm{~mm} \mathrm{NaF,} 0.2 \mathrm{~mm}$ PMSF, and 1:100 dilution protease inhibitor mixture (Sigma). Protease and phosphatase inhibitors were added to lysis buffer stock solution immediately before use. Once tissue was homogenized, it was allowed to rest on ice for $30 \mathrm{~min}$ (vortexed briefly after $15 \mathrm{~min}$ ). Tissue was centrifuged for $10 \mathrm{~min}$ at $14,000 \times g$ at $4^{\circ} \mathrm{C}$ and supernatant collected. Protein concentrations were determined using the DC protein assay (Bio-Rad). DTT was added to 30 $\mu \mathrm{g}$ of protein (final concentration $0.07 \mathrm{M}$ ); samples were then boiled for $5 \mathrm{~min}$ and separated by SDS-PAGE as previously described (Tyler et al., 2009).

RNA isolation and RT-PCR analysis. Tissues were harvested and frozen in the same manner as for protein analysis. For RNA isolation, tissues were homogenized immediately in $1 \mathrm{ml}$ of TRIzol reagent (Invitrogen). RNA was isolated according to the TRIzol protocol provided by Invitrogen. RNA concentration was measured using a NanoDrop spectrophotometer (Thermo Scientific); $1.5 \mu \mathrm{g}$ of RNA was used to reverse transcribe cDNA using Superscript II (Invitrogen). Spinal cord RNA was further purified using chloroform (Sigma) and precipitated with sodium acetate.

Concentrations of cDNA were determined by spectrophotometry, and working aliquots were stored at $-20^{\circ} \mathrm{C}$ before RT-PCR. For RT-PCR, $100 \mathrm{ng}$ of cDNA was used as a template in reactions containing $1 \times$ SYBR Green detection master mix and $1 \times$ Quantitect primer mix to detect the mRNA levels of MBP, PLP, MOG, MAG, and MRF (QIAGEN). Amplification was normalized to expression levels of $\beta$-actin (IDT) for each sample. RT-PCR was performed on the Applied Biosystems 7900B and (7500) using the associated Sequence Detection System Version 2.2.2 and (2.0.1). The thermal reaction profiles were performed as previously described (Tyler et al., 2009).

Analysis of recombination. Spinal cords were isolated and frozen in the same manner as for protein and RNA isolation. Tissues were homogenized in a 50:50 solution of phenol and chloroform; $200 \mu \mathrm{l}$ TE (10 mM Tris- $\mathrm{HCl}, 1 \mathrm{~mm}$ EDTA) was added to bring the solution up to a working volume. Homogenized tissues were centrifuged at 14,000 rpm for $1 \mathrm{~min}$ at room temperature. The aqueous phase was transferred to a fresh tube, 


\section{A}
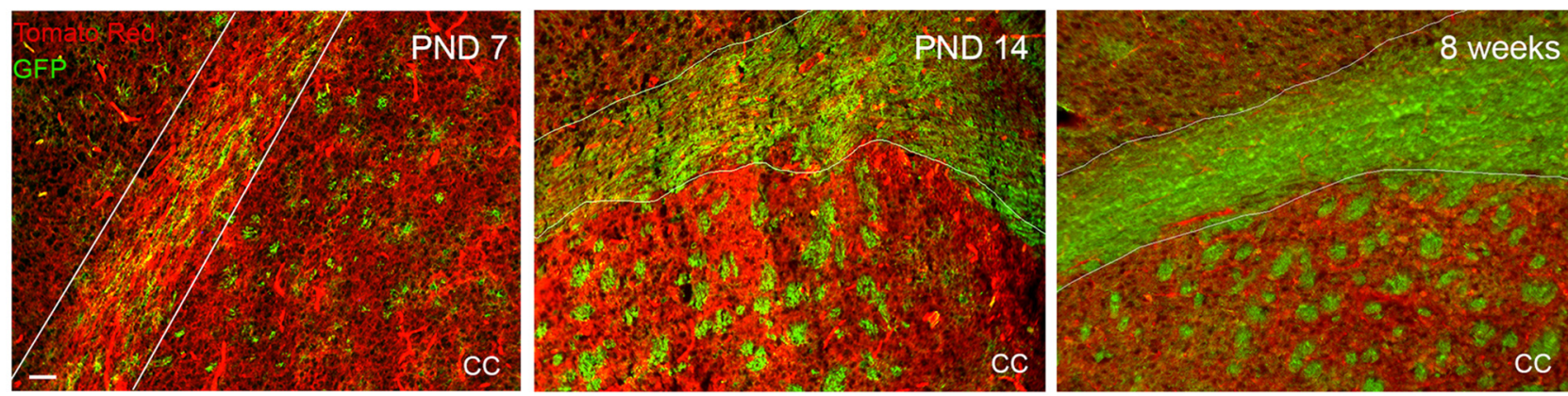

B

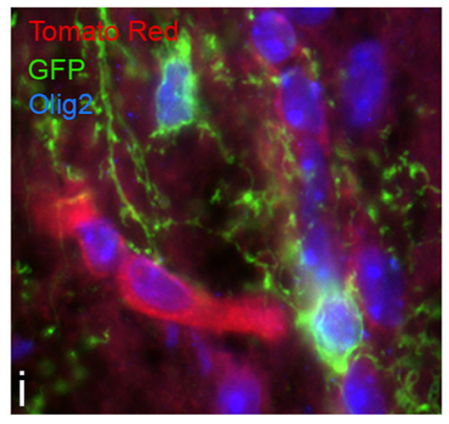

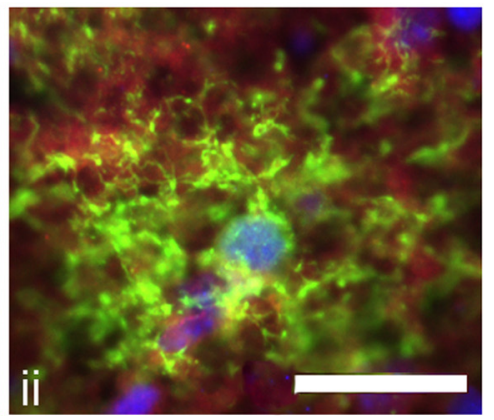

C

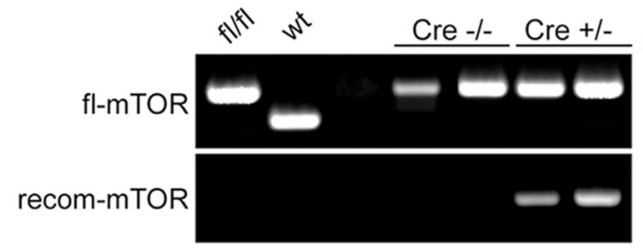

D

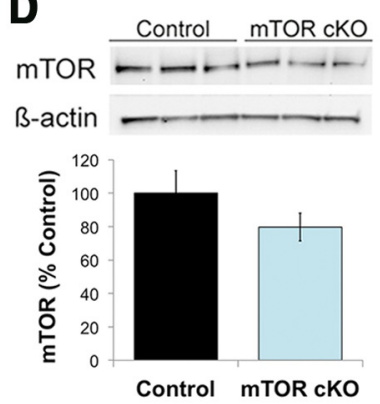

E

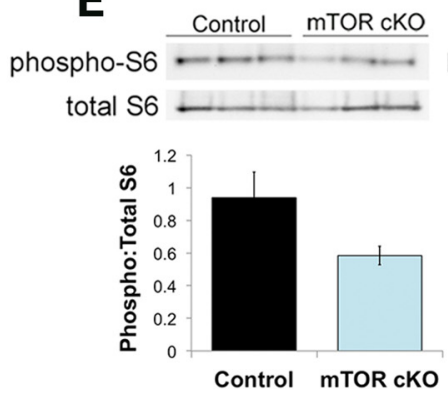

F

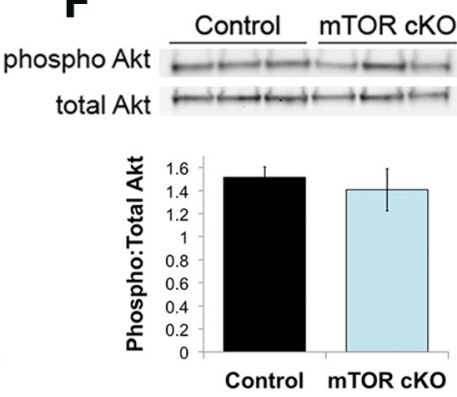

G

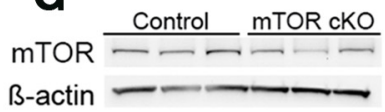

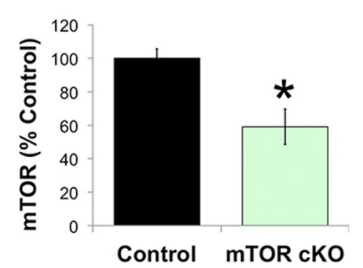

H
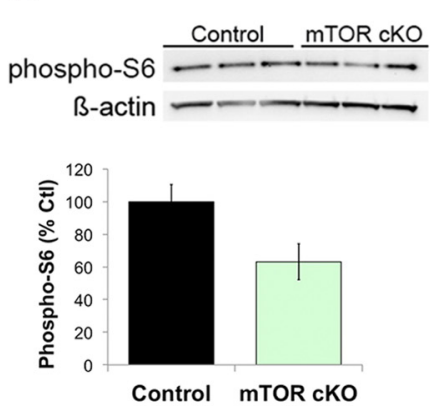

I
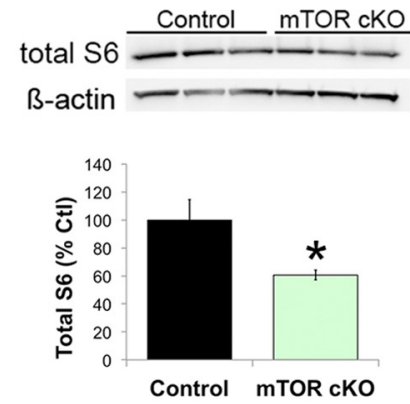

J
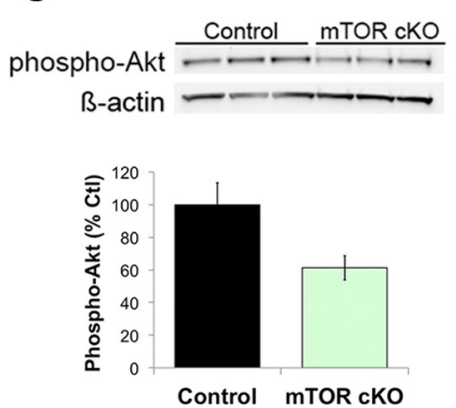

\section{K}
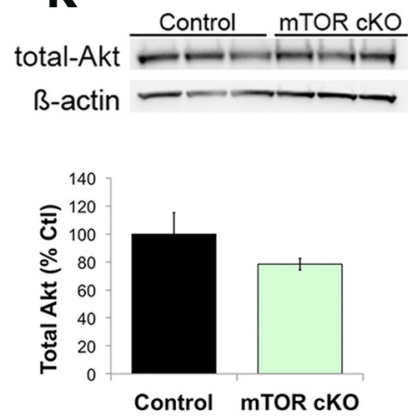

Figure 1. mTOR expression is reduced in the mTOR cKO. $\boldsymbol{A}$, GFP reporter expression induced by active Cre recombinase in white matter at PND7, PND14, and 8 weeks. $\boldsymbol{B}$, Images of individual recombined (GFP ${ }^{+}$, green), Olig2 ${ }^{+}$(blue) cells $(i, i i)$, and nonrecombined (Tomato Red ${ }^{+}$) 0 lig2 ${ }^{+}$(blue) cells (i) at PND7 in the corpus callosum of the mTOR cK0. C, PCR products amplified from PND14 spinal cord genomic DNA showing the floxed-mTOR (fl-mTOR) and the recombined-mTOR (recom-mTOR) alleles. D-F, Representative Western blots and quantification of mTOR, Phospho: total S6 ribosomal protein, and Phospho:total Akt expression in PND14 spinal cord. Blue bars represent PND14 mTOR cK0. G-K, Representative Western blots and quantification of mTOR, P-S6, total S6, P-Akt, and total Akt expression in PND25 spinal cord. Green bars represent PND25 mTOR cK0. Quantifications are expressed as percentage control, with the exception of the ratio of Phospho:total S6 and Phhospho:total Akt at PND14. Scale bars: $\boldsymbol{A}, 100 \mu \mathrm{m} ; \boldsymbol{B}, 50 \mu \mathrm{m}$. All statistical comparisons were conducted with a Student's $t$ test. ${ }^{*} p<0.05$.

and an equal volume of phenol chloroform was added. This process was repeated until there was no visible protein at the interface between the organic and aqueous phases after centrifugation. An equal volume of chloroform was added to the aqueous phase, and the solution was spun again at 14,000 rpm for $1 \mathrm{~min}$ at room temperature. The chloroform wash was repeated until there was no interphase. DNA was recovered by precipitation with sodium acetate and ethanol. DNA was resuspended in $\mathrm{TE}$, and the purity was determined using a spectrophotometer. Utilizing the same primers used for genotyping (IDT), 2 PCRs were set up to amplify floxed alleles and recombined alleles as previously described (Carr et al., 2012).

Tissue preparation and electron microscopy (EM). Animals were anesthetized and transcardially flushed with RPMI:heparin (described above), followed by perfusion with 4\% PFA, 2\% glutaraldehyde in PBS. Brains and spinal cords were removed and stored in additional fixative before processing. Corpus callosum was isolated from $1 \mathrm{~cm}$ coronal slices 


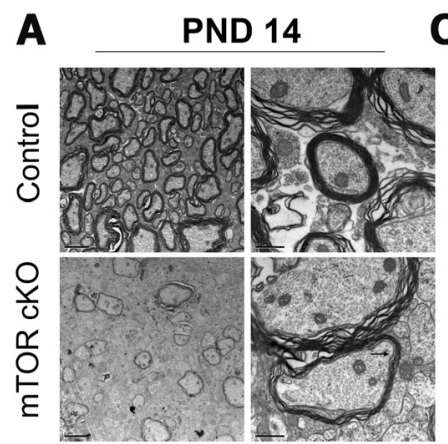

C 8 weeks

B

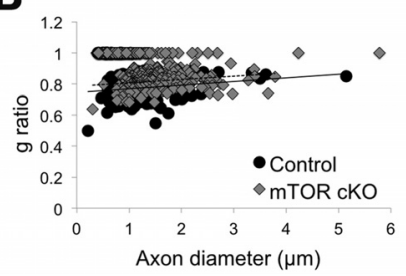

D

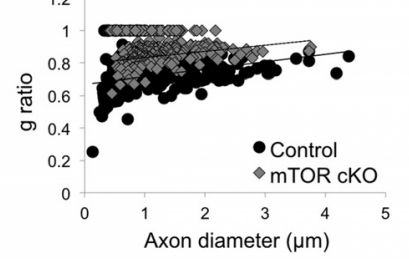

Figure 2. The extent of myelination is significantly reduced in mTOR cKO spinal cord. $\boldsymbol{A}, \boldsymbol{C}$, Representative electron micrographs from the spinal cord of control or mTOR cKO animals at PND14 (A) and 8 weeks (C). Scale bars: left, $2 \mu \mathrm{m}$; right, $0.5 \mu \mathrm{m}$. $\boldsymbol{B}, \boldsymbol{D}$, Scatter plots of G-ratios of representative animals at PND14 $(\boldsymbol{B})$ and 8 weeks $(\boldsymbol{D})$. G-ratio measurements were performed on $\geq 200$ axons/animal; $n=3$ /group. $p \leq 0.01$ at both time points.

of brain between -0.94 and -2.18 of bregma (Franklin and Paxinos, 2008). Spinal cords were cut into $1 \mathrm{~mm}$ coronal sections through the cervical enlargement. All tissue was postfixed in 1\% osmium, dehydrated in graded acetone, and resin embedded in Embed 812 (EMS) using a Pelco Biowave Pro Tissue processor (Ted Pella). The corpus callosum pieces were oriented such that sections could be cut midline in a sagittal plane. Spinal cord pieces were oriented such that sections could be cut in a transverse plane. Ultrathin sections $(80 \mathrm{~nm})$ were mounted on copper grids and stained with uranyl acetate and lead citrate and viewed at $80 \mathrm{kV}$ on a Technai G2 transmission electron microscope (FEI).

EM analyses were performed on three animals per genotype; a minimum of 200 myelinated axons was counted per animal. The g-ratio of axons was obtained by determining the ratio of the circumference of the axon alone to the circumference of the fiber (axon and myelin). The circumference of all visible axons was measured, regardless of myelination. In addition, the numbers of myelinated and unmyelinated axons were counted.

\section{Results}

\section{mTOR expression is reduced in the mTOR cKO mouse}

To selectively remove mTOR from oligodendrocytes in the CNS, we generated mTOR cKO mice as described in Materials and Methods. These mice were viable, able to reproduce, and exhibited no visible phenotype (seizures or shaking). mTOR cKO mice were produced at expected Mendelian ratios and had normal lifespans. GFP reporter expression, driven by active Cre recombinase, was examined in mTOR cKO mice beginning at day 7 in the brain (Fig. 1 A,B). GFP expression increased from $7 \mathrm{~d}$ to $14 \mathrm{~d}$ in white matter areas of the brain (Fig. $1 A$ ). At $7 \mathrm{~d}$, there were Olig2 ${ }^{+}$oligodendrocytes within the corpus callosum that were nonrecombined (Fig. $1 \mathrm{Bi}$ ) as well as Olig2 ${ }^{+}$cells that were recombined (Fig. 1Bii). Cells of both simple and complex branched morphology expressed GFP, but all were Olig $2^{+}$. The majority of cells in white matter tracts expressed GFP by PND14 (Fig. 1A). Robust GFP expression persisted into adulthood and was observed at all time points examined, indicating active Cre recombinase in the majority of cells in the white matter tract from PND14 through adulthood.
To further characterize recombination of the $m T O R$ alleles in the mTOR cKO, genomic DNA was isolated from spinal cords of PND14 mice and used for PCR amplification to detect either the floxed-mTOR allele or the recombined allele (Fig. 1C). The nonrecombined floxed allele amplified from DNA isolated from both control mice and mTOR cKO (Fig. 1C, top band) as expected because the spinal cord isolates contained neurons and other glial cell types. Primers designed to amplify the recombined allele produced a band in DNA isolated from the mTOR cKO spinal cords but not in control spinal cords (Fig. 1C, bottom). These data confirmed recombination of the mTOR allele in the mTOR cKO.

mTOR protein expression was reduced but not significantly decreased in the spinal cord at PND14 (Fig. 1D), consistent with the presence of nonrecombined neurons and other glial cell types in the spinal cord. Phosphorylation of ribosomal protein S6, a downstream target of the mTORC1 complex, was also reduced in the mTOR cKO spinal cords at PND14, although, as with mTOR, this reduction did not reach statistical significance (Fig. 1E; $p=$ 0.09). Phosphorylated Akt at serine 473, a target of mTORC2, was unchanged in the spinal cord at PND14 (Fig. $1 F$ ).

At PND25, mTOR protein expression was significantly reduced in the spinal cord, despite neuronal contamination (Fig. $1 G ; p=0.02$ ). Phosphorylation of 66 was reduced but not statistically significant (Fig. $1 H ; p=0.07$ ); however, total 66 protein expression was significantly reduced at this time point (Fig. 1I; $p=0.05)$. Unlike PND14, the phosphorylation of Akt at Ser473 was moderately decreased in the PND25 spinal cord (Fig. 1j; $p=$ 0.06). The total levels of Akt were unchanged in the PND25 spinal cord (Fig. $1 \mathrm{~K}$ ). These results provide evidence for $m$ TOR deletion in the CNS of the mTOR cKO and support the conclusion that signaling of both mTORC1 and mTORC2 is affected.

\section{A lack of mTOR in oligodendrocytes results in hypomyelination of the spinal cord}

We have previously shown that the ability of oligodendrocytes to produce myelin is impaired in oligodendrocytes when mTOR is inhibited in vitro (Tyler et al., 2009). To investigate whether myelination was impaired in the mTOR cKO, we examined spinal cords by EM. Myelinated axons of the spinal cord in the mTOR cKO had significantly thinner myelin at PND14 (Fig. 2A). The extent of myelination, quantified by determining g-ratios, confirmed these findings (g-ratio control $=0.77$, g-ratio $\mathrm{mTOR} \mathrm{cKO}=0.83 ; p=0.01$ ). A representative scatter plot (Fig. $2 B$ ) shows the distribution of g-ratios as a function of axon diameter for a representative control and mTOR cKO. The cluster of data points with a g-ratio of 1 indicates unmyelinated axons. The myelination that did occur appeared normal, although thin, with compact loops and an intact periaxonal collar (Fig. 2A, arrow).

We then examined whether or not the deficit in myelination during development persisted in the adult CNS. The extent of myelination at 8 weeks remained impaired; the mTOR cKO spinal cords had a significantly larger g-ratio than control (g-ratio control $=0.73$, g-ratio mTOR $c K O=0.82 ; p=0.003$; Fig. $2 D$, representative scatter plot). As for PND14, the structure of the myelin that formed appeared normal.

\section{Initiation of myelination is impaired in the mTOR cKO spinal cord}

The EM analyses suggested the mTOR cKO had fewer myelinated axons, particularly at PND14 (Fig. 2A). Thus, we quantified the percentage of unmyelinated axons in the spinal cord (Fig. 3). In the control spinal cord, $11 \%$ of axons were unmyelinated at 

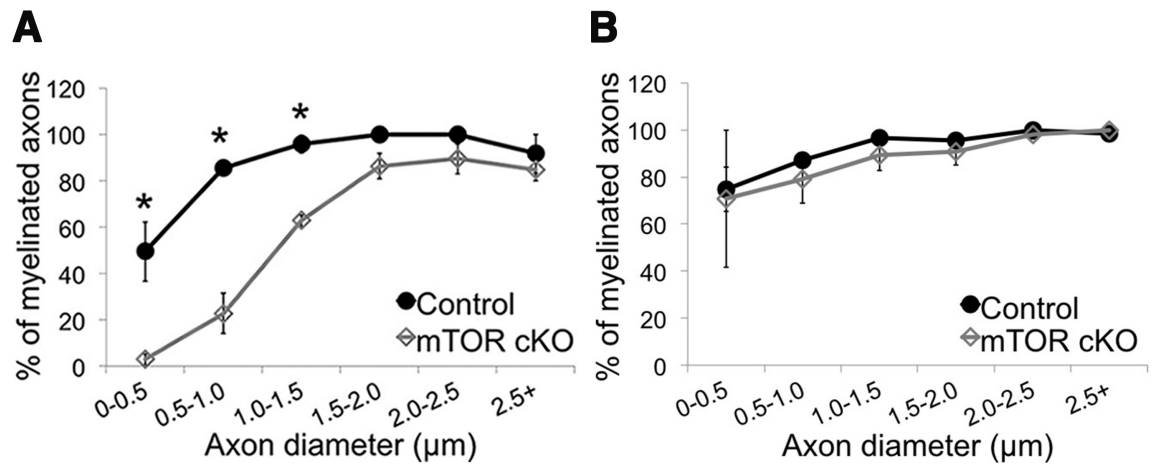

Figure 3. Lack of $m$ TOR results in a deficit in the initiation of myelination. Quantification of the percentage of axons that were myelinated in relation to axon diameter at PND14 $(\boldsymbol{A})$ and 8 weeks $(\boldsymbol{B})$. Differences in myelination were compared using two-way ANOVA and Tukey's post hoc test. *Significant differences in percentage myelinated axons at a given diameter ( $p \leq 0.02)$.

(Fig. $4 G ; p=0.03$ ). Despite the increased MAG mRNA at 8 weeks, MAG expression was not significantly altered at any time point examined (Fig. $4 H$ ). Together, these data indicate that mTOR has differential effects on expression of myelin proteins, with the most pronounced deficits seen in PLP/DM20 and MOG during development in the mTOR cKO. Expression of most myelin proteins recovered by 8 weeks, with the exception of MBP expression.

\section{Oligodendrocyte differentiation is impaired in the mTOR cKO spinal cord during development}

The analyses of myelination presented

PND14. In contrast, $52 \%$ of axons were unmyelinated in the spinal cord of the mTOR cKO $(p=0.0003)$. Oligodendrocytes in the CNS myelinate axons with larger diameters first during development (Baumann and Pham-Dinh, 2001). When the percentage of myelinated axons was analyzed by axon diameter, we saw a clear deficit in percentage of myelinated axons of diameters $\leq 1.0 \mu \mathrm{m}$ ( $p \leq 0.02$, two-way ANOVA, Tukey's HSD) (Fig. $3 A)$. We found no difference in the diameter of unmyelinated or myelinated axons ( $p=0.1$ for both genotypes). At 8 weeks of age, there was no significant difference in the percentage of myelinated axons at any specific diameter in the spinal cord (Fig. 3B); however, the average diameter of an unmyelinated axon was significantly larger in the mTOR cKO than in the control $(p=0.03)$, which suggests that some deficit in myelin initiation persisted into the adult.

\section{Myelin protein expression is altered in the mTOR cKO spinal cord}

The EM analyses indicated deficits in spinal cord myelination with loss of mTOR in oligodendrocytes. To determine effects on specific myelin proteins, we examined expression of specific myelin proteins in the spinal cord at PND14, PND25, and 8 weeks. We first examined the major myelin proteins MBP and PLP. In the mTOR cKO spinal cord, MBP protein expression appeared reduced at all time points examined, but the reduction was significant only at PND25 and 8 weeks (Fig. $4 B ; p \leq 0.03$ ). mRNA expression was examined at PND14 and 8 weeks. MBP mRNA expression was not significantly changed at either time (Fig. 4A). In contrast, the mRNA transcript for PLP/DM20 was significantly reduced at both time points examined (Fig. $4 C ; p<0.001$ ). Protein expression of PLP and its splice variant DM20 were reduced at PND14 (Fig. 4D; $p \leq 0.01$ ), consistent with the reduction in mRNA at this time. In contrast to the mRNA expression, levels of both PLP and DM20 proteins had recovered to control levels by PND25 and remained comparable with control levels at 8 weeks (Fig. $4 D$ ).

MOG, a minor component of myelin that is expressed later in development, was significantly reduced at both the mRNA (Fig. $4 E$ ) and protein (Fig. $4 F$ ) levels at PND14 ( $p \leq 0.02)$. At PND 25, MOG-protein in the $\mathrm{mTOR} \mathrm{cKO}$ was no longer significantly different than control levels (Fig. 4F). At 8 weeks, MOG mRNA and protein expression in the mTOR cKO were comparable with control levels (Fig. 4E,F). mRNA expression of MAG, another minor component of myelin with a role in myelin compaction, was unaffected in the mTOR cKO at PND14; however, MAG mRNA was significantly increased in the spinal cord at 8 weeks above revealed a deficit in the initiation and extent of myelination in the spinal cord as well as a developmental delay in expression of specific myelin proteins. Our prior studies and the work of others showed that either pharmacological inhibition or knockdown of mTOR blocked the differentiation of oligodendrocytes at various stages in vitro (Tyler et al., 2009; Guardiola-Diaz et al., 2012). To determine whether the observed effects on myelination were a consequence of impaired differentiation, we analyzed expression of PDGF-receptor $\alpha$ (PDGFR $\alpha$ ), a marker of early OPCs (Richardson et al., 2000; Spassky et al., 2000) and of the adenomatous polyposis coli (also known as CC1) protein, used to identify mature oligodendrocytes (He et al., 2007; Lytle et al., 2009; Fancy et al., 2011), in relation to total numbers of oligodendroglia (Olig2 ${ }^{+}$cells). Overall, the total number of Olig2 ${ }^{+}$cells did not change between control and mTOR cKO spinal cord at PND14 (Fig. 5A, quantified in Fig. 5B). This indicates that the lack of mTOR had no effect on the total number of oligodendrocytes present in the developing spinal cord. Moreover, there was no change in the number of Olig2 ${ }^{+}$cells that were PDGFR $\propto^{+}$(Fig. $5 A$, quantified in Fig. $5 C$ ). However, there was a significant decrease in the number of Olig ${ }^{+}$cells that were $\mathrm{CC}^{+}{ }^{+}$(Fig. $5 \mathrm{~A}$, quantified in Fig. 5D; $p=0.02$ ).

To assess whether proliferation of the OPCs at any stage was altered in vivo by loss of mTOR, we coimmunostained for the proliferation marker Ki67 with Olig2. There was no difference in the number of $\mathrm{Ki}^{+} 7^{+} / \mathrm{Olig} 2^{+}$cells in the control versus mTOR cKO (control, $3.6 \pm 0.36$; vs mTOR cKO, $3.7 \pm 0.42, p=0.9$ ) at PND14. These analyses support the hypothesis that mTOR is not required for OPC proliferation but that it regulates oligodendrocyte differentiation in the spinal cord at PND14.

\section{A deficit in mature oligodendrocytes in the mTOR cKO persists in adult spinal cord}

Oligodendrocyte differentiation was impaired during the development of the mTOR cKO spinal cord. Although myelin protein expression, with the exception of MBP (Fig. 4B), as well as the percentage of myelinated axons (Fig. $3 B$ ) recovered in the adult mTOR cKO spinal cord, it is possible that the reduction in mature oligodendrocytes persisted. To address this possibility, we quantified the number of $\mathrm{CC}^{+}{ }^{+}$cells in adult spinal cord sections (Fig. 6A). The average number of cells within the white matter that were $\mathrm{CCl}^{+}$was lower in the mTOR cKO than in the control animals $\left(78 \mathrm{CC}^{+} / \mathrm{DAPI}^{+}\right.$ cells/section in control vs $58 \mathrm{CC}^{+} / \mathrm{DAPI}^{+}$in $\mathrm{mTOR} \mathrm{cKO}$, $p<0.01$; Fig. $6 B$ ). These data suggest that the effect of mTOR 
A

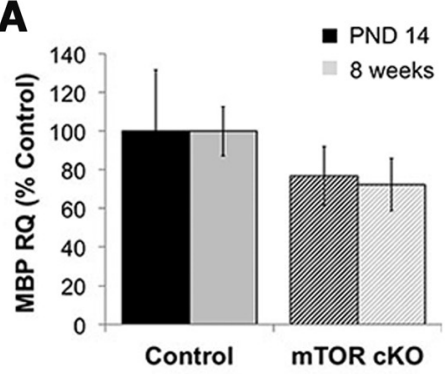

C

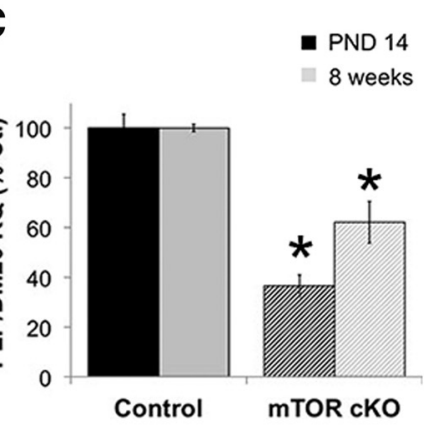

E

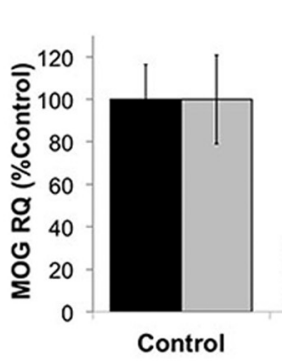

G

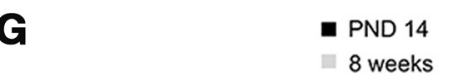

- PND 14

8 weeks

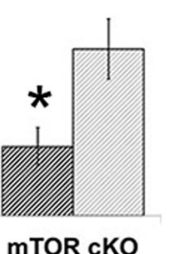

8 weeks
B

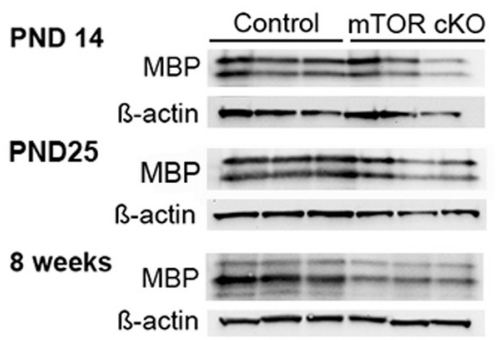

D

- PND 14

ㅁ PND 25

8 weeks

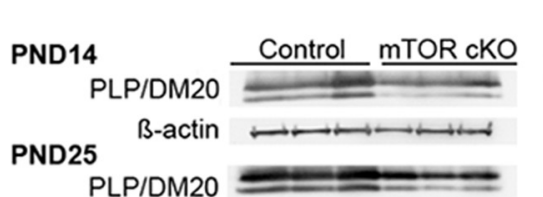

PLPIDM20

ß-actin

8 weeks

PLP/DM20

ß-actin

$\mathbf{F}$

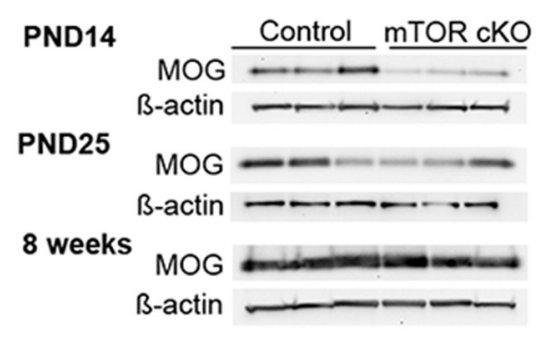

H
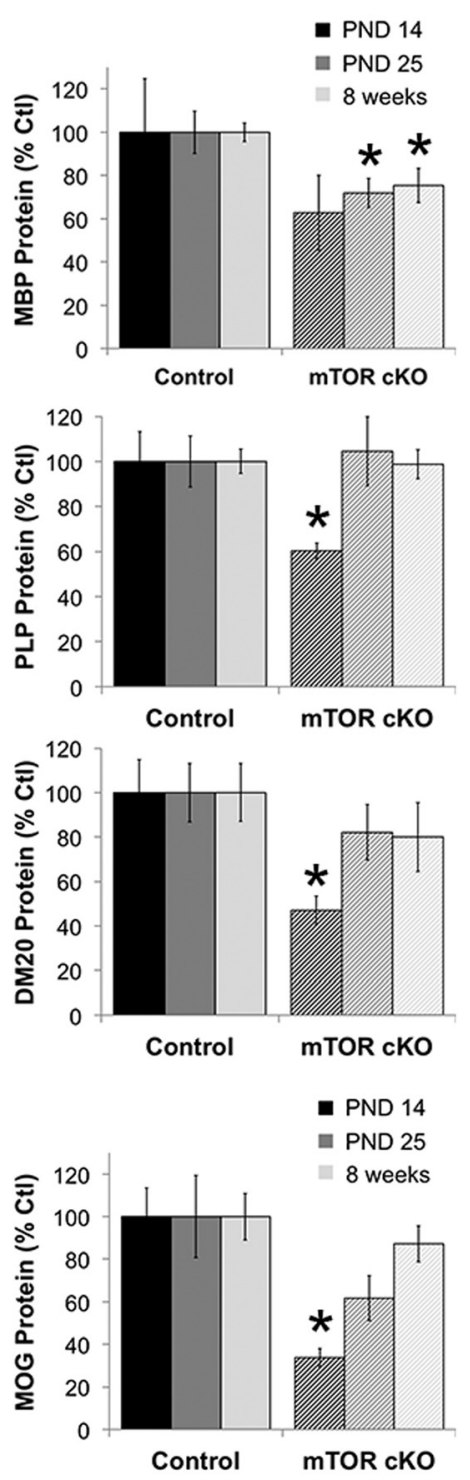

- PND 14

PND 25
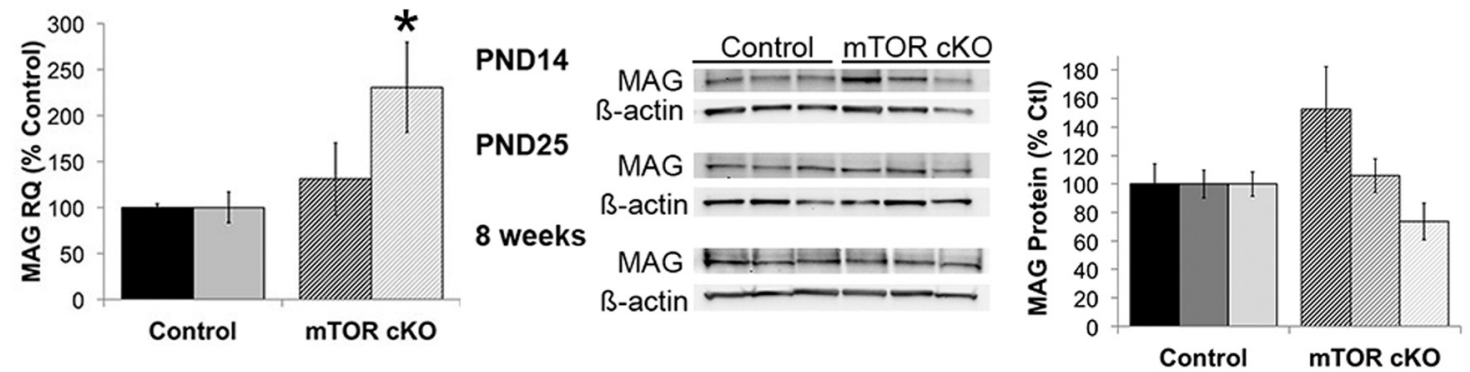

Figure 4. Myelin protein and mRNA expression in the spinal cord of mTOR cKO. mRNA $(\boldsymbol{A}, \boldsymbol{C}, \boldsymbol{E}, \boldsymbol{G})$ and protein $(\boldsymbol{B}, \boldsymbol{D}, \boldsymbol{F}, \boldsymbol{H})$ expression was examined for MBP $(\boldsymbol{A}, \boldsymbol{B}), \operatorname{PLP} / \mathrm{DM} 20(\boldsymbol{C}, \boldsymbol{D}), \operatorname{MOG}(\boldsymbol{E}, \boldsymbol{F})$, and MAG $(\boldsymbol{G}, \boldsymbol{H})$ in isolated spinal cord at the onset of myelination (PND14) and in the adult (8 weeks). Representative blots at each time point are shown for protein expression. $\mathrm{mRNA}$ analyses were performed on $n=6 /$ group from at least two independent litters. Protein analyses were performed on $n=9 /$ group from at least two independent litters. All quantifications are expressed as percentage control \pm SE. ${ }^{*} p \leq 0.05$.

loss on oligodendrocyte differentiation was not compensated for by another mechanism.

The role of $\mathrm{mTOR}$ in the brain

To determine whether the decreased oligodendrocyte differentiation and reduced myelination observed in the spinal cord persisted in the brain, we examined cerebellum and cortex of mTOR
cKO mice. Because myelination occurs later in the brain than in the spinal cord (Foran and Peterson, 1992; Baumann and PhamDinh, 2001), we examined PND14 to determine myelin protein expression at the onset of myelination, as well as PND25 to examine the expression at the peak of myelination. Similar to the spinal cord analyses, we examined brains at 8 weeks to determine the effects of the mTOR cKO in the adult. 

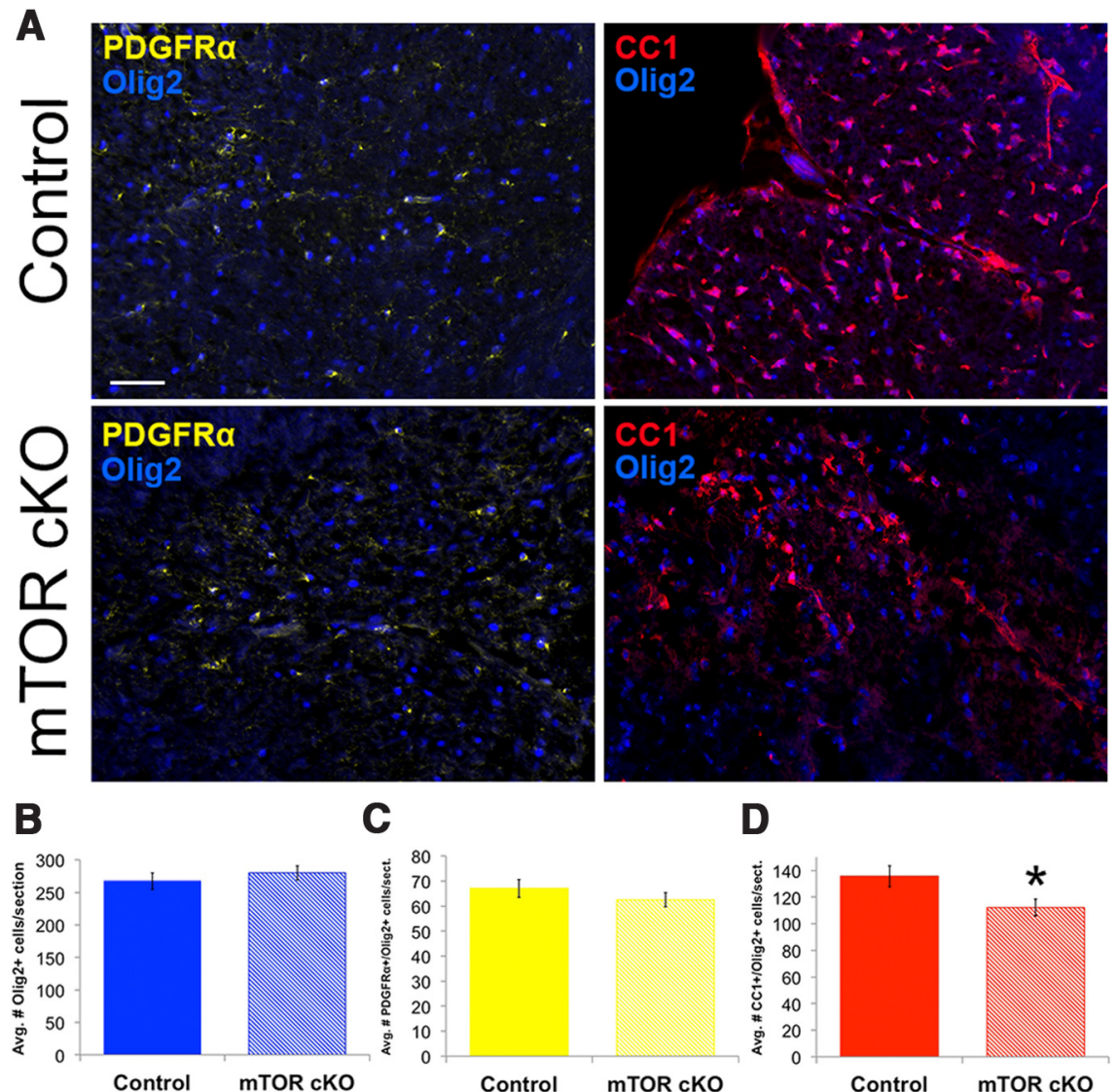

D

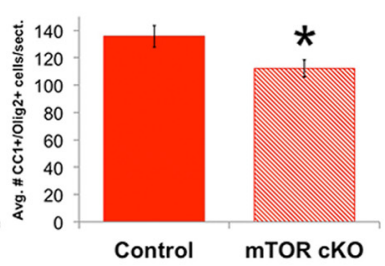

Figure 5. Differentiation is impaired in the mTOR cKO spinal cord during development. $\boldsymbol{A}$, Representative images of PDGFR $\propto$ (yellow)/0lig2 (blue; nuclear) or CC1 (red)/0lig2 (blue; nuclear) immunofluorescence to identify progenitors and mature oligodendrocytes in the spinal cord at PND14. Scale bar, $100 \mu \mathrm{m}$. $\boldsymbol{B}-\boldsymbol{D}$, Quantification of average number 0lig2 ${ }^{+}$cells $(\boldsymbol{B}), \mathrm{PDGFR}^{+} /$ Olig2 ${ }^{+}$cells $(\boldsymbol{C})$, and $\mathrm{CC}^{+}{ }^{+} / 0$ lig2 ${ }^{+}$cells per section $(\boldsymbol{D}) .{ }^{*} p \leq 0.05$.

MBP mRNA levels in the cerebellum of the mTOR cKO were not significantly altered at any time point in the mTOR cKO (Fig. $7 A$ ). MBP protein was reduced during development by $50 \%$ at both PND14 and PND25 $(p<0.01)$ but recovered in the adult $(p=0.69)$ (Fig. 7B). PLP/DM20 mRNA expression was reduced at PND14 and at 8 weeks (Fig. $7 C ; p=0.02$ at PND14, $p=0.08$ at PND25, and $p=0.05$ at 8 weeks). PLP protein was reduced during development by $60 \%$ ( $p=0.04$ at PND14 and $p<0.01$ at PND25) but, like MBP, was comparable with control levels in the cerebellum at 8 weeks (Fig. 7D). DM20 protein expression was reduced during development and remained reduced in the adult (PND14 $p<0.05, p=0.07$ at PND25, 8 weeks $p<0.005$; Fig. $7 D)$. Overall, the major myelin proteins were expressed at lower levels in the mTOR cKO cerebellum during development, like the spinal cord. Unlike the spinal cord, both MBP and PLP expression recovered in the adult. The effect of mTOR loss on mRNA expression of major myelin proteins MBP and PLP was similar in the cerebellum and the spinal cord. The reduction of DM20 in the mTOR cKO at 8 weeks was unique to the cerebellum (Fig. 7D).

The effect of mTOR deletion on MOG expression was less severe in the cerebellum than in the spinal cord; MOG mRNA levels were unaffected at any time point (Fig. $7 E$ ), and MOG protein levels were moderately reduced at PND14 and significantly reduced at PND25 (Fig. 7F; $p=0.07$ at PND14, $p=0.01$ at PND25). MAG mRNA levels were unaffected in the mTOR cKO cerebellum during development and showed a trend to increase at 8 weeks (Fig. $7 G$ ). MAG protein expression was decreased $(p<$
$0.01)$ at PND25. This decrease persisted and at 8 weeks $(30 \%$ reduction, Fig. $7 \mathrm{H}$; $p=0.04)$.

Consistent with the more posterior CNS regions, MBP mRNA was unaltered in the cortex of the mTOR cKO (Fig. 8A). MBP protein expression also was comparable with the expression profile in the cerebellum and the spinal cord with a moderate $(\sim 50 \%)$ reduction at PND14 and PND25 (Fig. $8 B ; p=0.07$ at PND14 and $p=0.03$ at PND25). The reduction in MBP protein levels at PND25 was the only myelin protein reduction that was consistent across all regions examined. Like the cerebellum, MBP protein expression in the mTOR cKO resembled control expression at 8 weeks (Fig. $8 B$ ). PLP/DM20 mRNA was moderately reduced $(\sim 40 \%$, $p=0.06$ ) at 8 weeks. Unlike the cerebellum and the spinal cord, PLP/DM20 mRNA levels were unchanged during development in the cortex of the mTOR cKO (Fig. 8C). PLP was comparable with control at PND25 and increased in the adult cortex of the mTOR cKO $(p=0.02)$ of the $\mathrm{cKO}$ (Fig. $8 D$, top). Expression of DM20 (Fig. 8D, bottom) was not significantly affected at any time point.

MOG mRNA and protein expression were more strongly inhibited in the mTOR cKO cortex compared with the cerebellum (Fig. 8E,F). mRNA expression was moderately reduced at PND25 $(p=0.07)$. This mirrored the expression in the mTOR cKO spinal cord where MOG mRNA was reduced during development but recovered to control levels in the adult. MOG protein was reduced at PND25 $(p=0.07)$ and remained moderately reduced at 8 weeks (Fig. 8F; $p=0.08)$. MAG mRNA expression appeared elevated at all time points and reached statistical significance at 8 weeks in the mTOR cKO (Fig. $8 G ; p=0.01$ ). Unlike the mRNA expression, MAG protein expression was significantly reduced at 8 weeks (Fig. $8 H$; $p=0.03)$. The reduction in MAG protein in the cortex was consistent in the brain and trended across the CNS of the mTOR cKO. The increase in MAG mRNA in the cortex was also recapitulated in the spinal cord.

Overall, the expression of major myelin proteins was altered during development in the mTOR cKO brain. At the mRNA level, the effects on the PLP/DM20 transcript were most severe with the transcript expression not reaching control levels in the adult. The major myelin proteins all recovered to control levels in the brain of the mTOR cKO by 8 weeks, which was distinct from MBP protein expression in the spinal cord where it remained significantly reduced at 8 weeks. PLP expression was elevated in the cortex at 8 weeks, also unique to this region. MOG expression was delayed in all structures examined; mRNA and protein expression was comparable with control in all regions by 8 weeks, except the cortex. MAG expression was most consistently affected at 8 weeks across the three regions with the transcript reduced and the protein elevated. The only persistent defect in myelin protein expression in the cortex and cerebellum of the adult was a deficit in MAG protein expression (Figs. $7 \mathrm{H}$ and $8 \mathrm{H}$ ). 


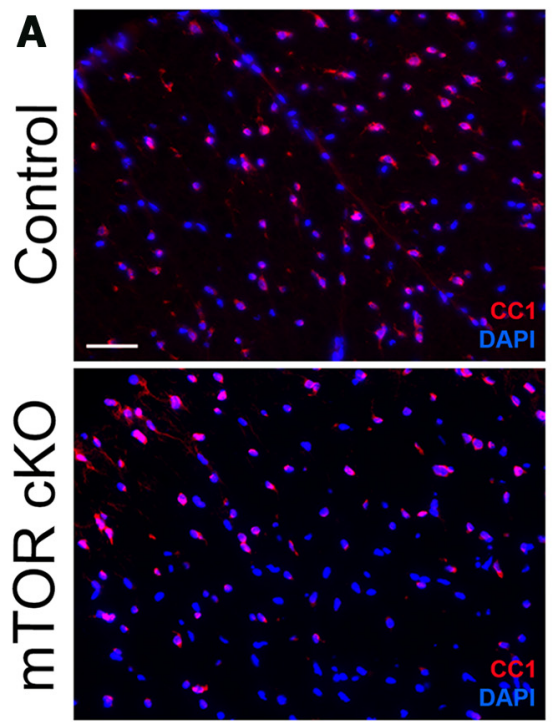

B

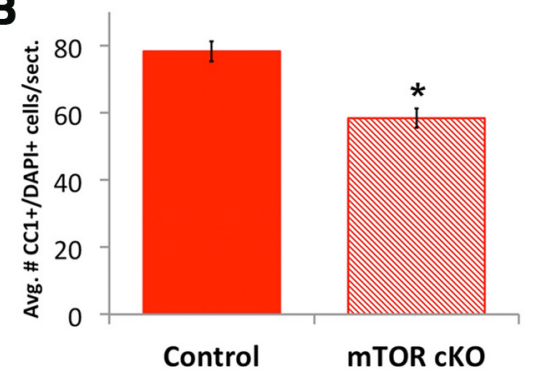

Figure 6. Differentiation is impaired in the $\mathrm{mTOR}$ cKO adult spinal cord. $A$, Representative images of CC1 (red)/DAPI (blue; nuclear) immunofluorescence to identify mature oligodendrocytes in the spinal cord at 8 weeks. Scale bar, $100 \mu \mathrm{m}$. B, Quantification of the number of $\mathrm{CC}^{+} / \mathrm{DAPI}^{+}$cells in the white matter. ${ }^{*} p<0.01$.

MAG is a cell-cell adhesion protein that functions in axonaloligodendrocyte contact and the maintenance of the periaxonal collar (Biffiger et al., 2000; Baumann and Pham-Dinh, 2001). The regulation of myelin protein expression varied in all regions of the CNS examined. The only consistent reduction across the CNS was that of MBP at PND25.

We examined the structure of myelin and the differentiation of OPCs in the corpus callosum to determine whether they were altered in the same manner as seen in the mTOR cKO spinal cord. EM of the corpus callosum at PND14 (Fig. 9A, left) and 8 weeks (Fig. 9A, right) revealed no difference in the structure or extent of myelination. At PND14, we observed axons with compact myelin and intact periaxonal collar in both the control and the mTOR cKO. No myelin abnormalities were observed in the mTOR cKO, and at 8 weeks the extent of myelination was indistinguishable between the control and the mTOR cKO in the corpus callosum (Fig. 9).

Although no deficits were observed in myelin thickness or initiation of myelination in the corpus callosum, the delay in myelin protein expression observed in the cortex and the cerebellum (deficits in protein expression at PND14 and PND25; Figs. 7 and 8 ) could be the result of a delay in differentiation, similar to what was seen in the spinal cord (Fig. 5B). To determine whether differentiation was delayed in the corpus callosum, the numbers of immature $\left(\mathrm{PDGFR} \propto{ }^{+} / \mathrm{Olig} 2^{+}\right)$and mature $\left(\mathrm{CC} 1^{+} / \mathrm{Olig} 2^{+}\right)$ cells were determined at PND14. The total number of Olig2 cells was unchanged (Fig. 9C). The percentage of PDGFR $\propto{ }^{+} / \mathrm{Olig} 2^{+}$ cells also was unaffected by loss of mTOR (Fig. 9D). Interestingly, the percentage of $\mathrm{CC}{ }^{+} / \mathrm{Olig} 2{ }^{+}$was significantly increased in the corpus callosum at $\operatorname{PND} 14(p=0.01$; Fig. $9 E)$.

\section{Discussion}

In the current study, we established an oligodendrocyte-specific knockdown of mTOR in the CNS to examine the role of mTOR in oligodendrocyte differentiation and myelination. We determined that mTOR promotes oligodendrocyte differentiation, initiation of myelination, and myelin thickness in the spinal cord. In contrast, mTOR is not essential for myelination in the brain; however, the expression of individual myelin proteins is delayed during development and abnormal in the adult cerebellum and cortex. This suggests that, although not essential for proper myelination, mTOR does have a role in the expression of myelin proteins in the brain in addition to its essential functions for proper myelination in the spinal cord.

The most pronounced phenotype we observed from deletion of mTOR in oligodendrocytes was in the spinal cord. In this region, there was a deficit in the number of mature oligodendrocytes during development that persisted into adulthood. This deficit was not the result of changes in the number of cells of the oligodendrocyte lineage as a whole. This suggests that mTOR has an essential role in oligodendrocyte differentiation that is unable to be compensated for in the spinal cord and is consistent with our prior in vitro data (Tyler et al., 2009). The block in differentiation by lack of mTOR in vivo coincided with a delay in the onset of myelination in the spinal cord. Although this suggests that the myelination delay was a consequence of impairment in differentiation, it does not rule out an independent effect of mTOR on the initiation of myelination. The existence of a separate effect on myelination in the CNS is supported by studies on the role of mTOR during development of the peripheral nervous system. Loss of mTOR in Schwann cells also resulted in delayed myelination and thinner myelin but had no effect on Schwann cell differentiation (Sherman et al., 2012). Additional work to separate the effects of mTOR on oligodendrocyte differentiation and myelination initiation are needed to definitively delineate these two potential functions.

Although there was no difference in the percentage of myelinated axons at 8 weeks of age, indicating recovery from the initiation deficit observed at PND14, the size of unmyelinated axons was slightly but significantly larger in the mTOR cKO adult. This indicates that a greater number of large-diameter axons in the mTOR cKO spinal cord remain unmyelinated. This suggests a persistent deficit in the initiation of myelination because largediameter axons are myelinated first and if initiation had completely recovered, there would be no difference in the distribution of axon diameters that were myelinated between the control and the mTOR cKO. Additionally, the persistence of thinner myelin in the adult spinal cord, as shown by EM and g-ratio analysis, suggests a role for mTOR in the extent of myelination that is independent of its function in myelin initiation. Therefore, both the initiation and extent of myelination are impaired in the spinal cord when mTOR is inhibited; and although there is significant recovery in initiation, neither process is complete without mTOR signaling.

Interestingly, although the expression of several myelin proteins was reduced at PND14, most of the myelin proteins had recovered to control levels by 8 weeks, with the exception of a $30 \%$ reduction in MBP protein. It is thus unlikely that deficits in myelin protein account for the persistence of the hypomyelination phenotype in the adult spinal cord. It is possible that mTOR 
A

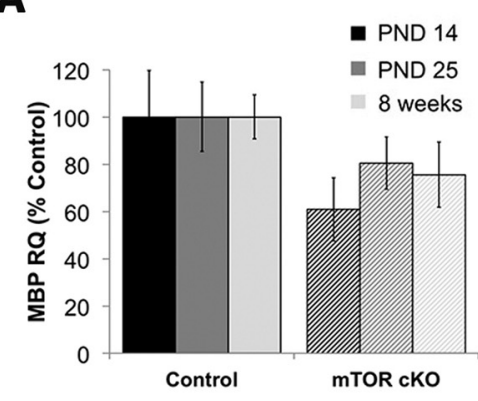

C

E
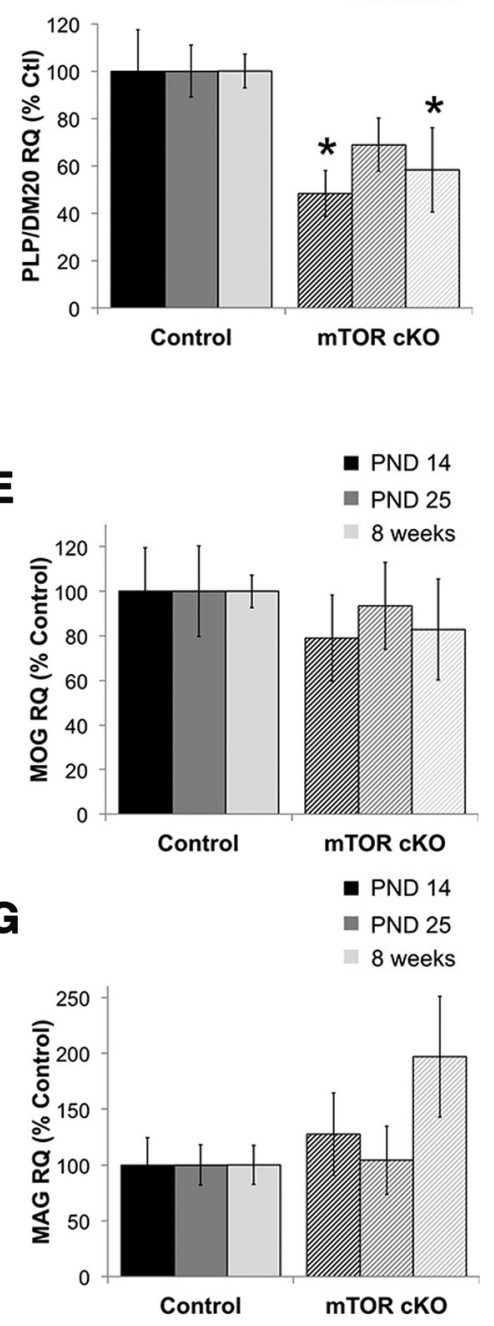

B

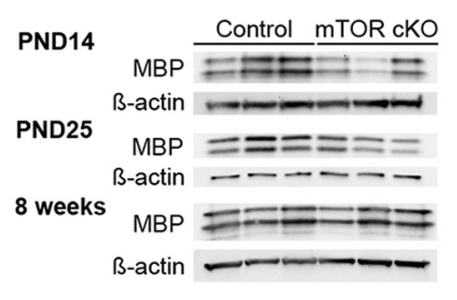

D

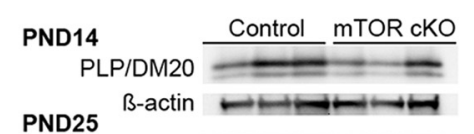

8 weeks ${ }^{\text {-actin }}-\cdots-\cdots$

PLP/DM20 $=$

B-actin $=$

$\mathbf{F}$

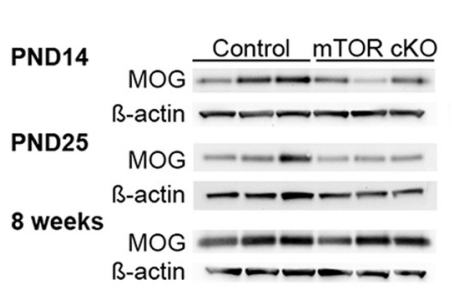

H

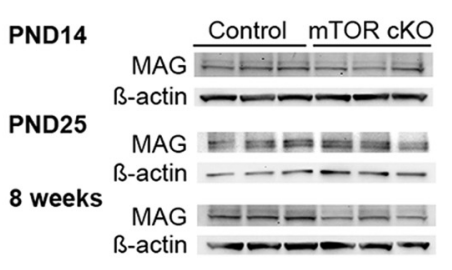

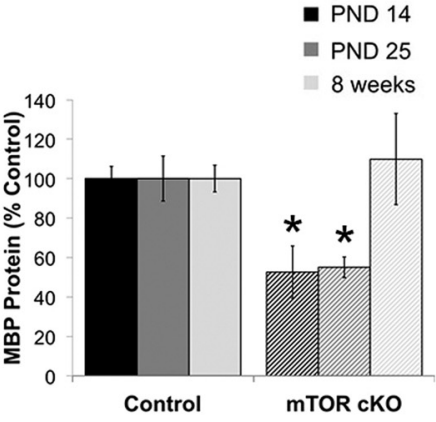
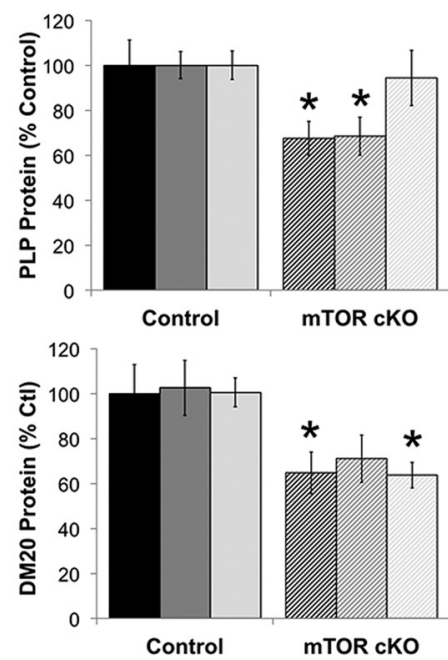

- PND 14

- PND 25

8 weeks

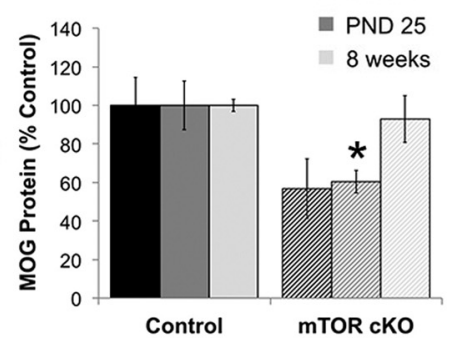

- PND 14

PND 25

8 weeks

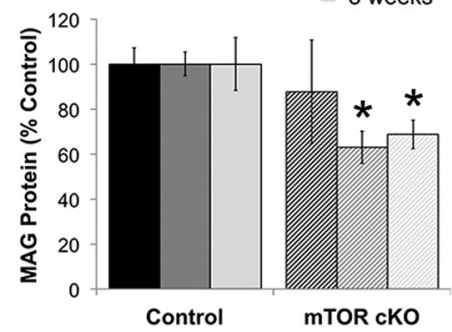

Figure 7. Myelin protein and mRNA expression in the cerebellum of $m$ TOR cK0. Myelin protein $(\boldsymbol{B}, \boldsymbol{D}, \boldsymbol{F}, \boldsymbol{H})$ and $\mathrm{mRNA}(\boldsymbol{A}, \boldsymbol{C}, \boldsymbol{E}, \boldsymbol{G})$ expression was determined for MBP $(\boldsymbol{A}, \boldsymbol{B}), \mathrm{PLP} / \mathrm{DM} 20(\boldsymbol{C}, \boldsymbol{D})$, and MOG $(\boldsymbol{E}, \boldsymbol{F})$ in isolated cerebellum of control and mTOR cKO mice at PND14, PND25, and 8 weeks. Representative blots at each time point are shown for protein expression. mRNA analyses were performed on $n=6 /$ group from at least two independent litters. Protein analyses were performed on $n=9 /$ group from at least two independent litters. All quantifications are expressed as percentage control $\pm S E .{ }^{*} p \leq 0.05$.

regulates other important mechanisms underlying myelination, such as cholesterol synthesis or proper trafficking of myelin proteins. We have recently shown that mTOR regulates key cholesterol synthesis and cytoskeletal proteins in vitro (Tyler et al., 2011). The recovery in myelin protein expression does suggest that the levels of myelin proteins are higher per cell because of fewer mature oligodendrocytes in the adult mTOR cKO spinal cord. The increased demand on each mature oligodendrocyte could result in the hypomyelination phenotype in the adult because they cannot generate the appropriate amount of my- 

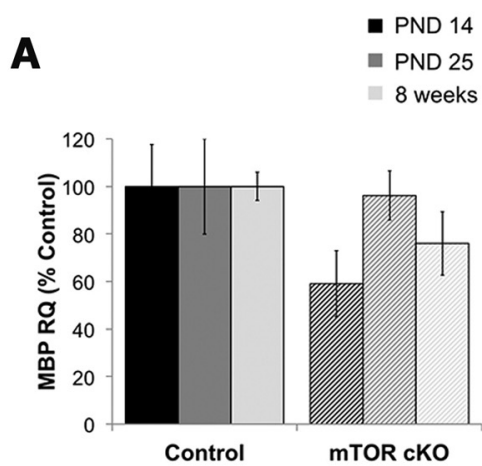

C

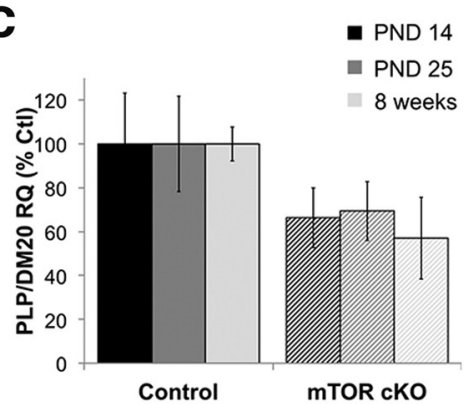

E

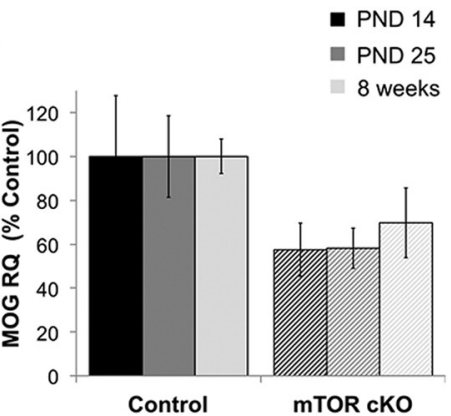

G

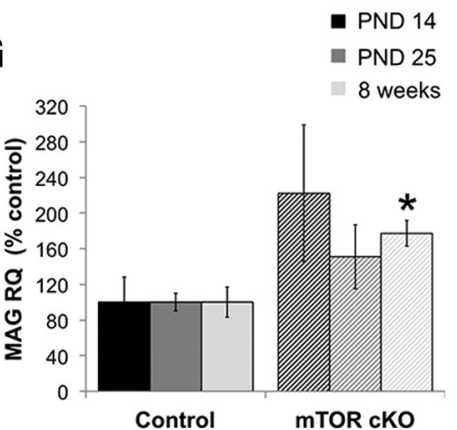

B

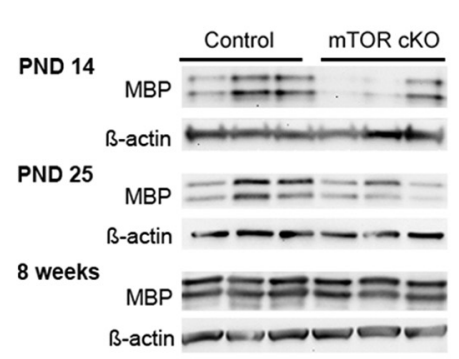

D

- PND 14

PND 25

8 weeks

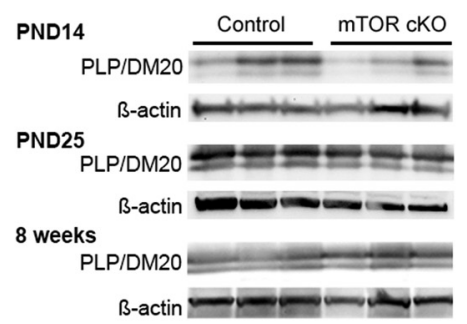

F

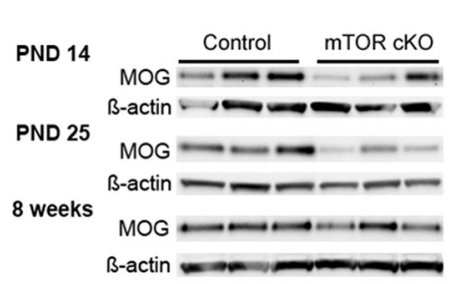

H

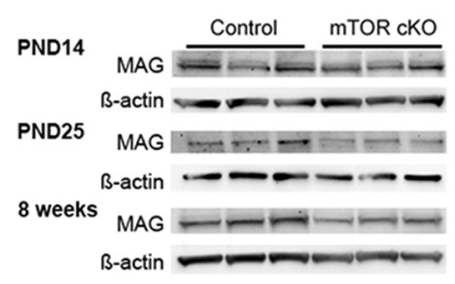

- PND 14

- PND 25

8 weeks
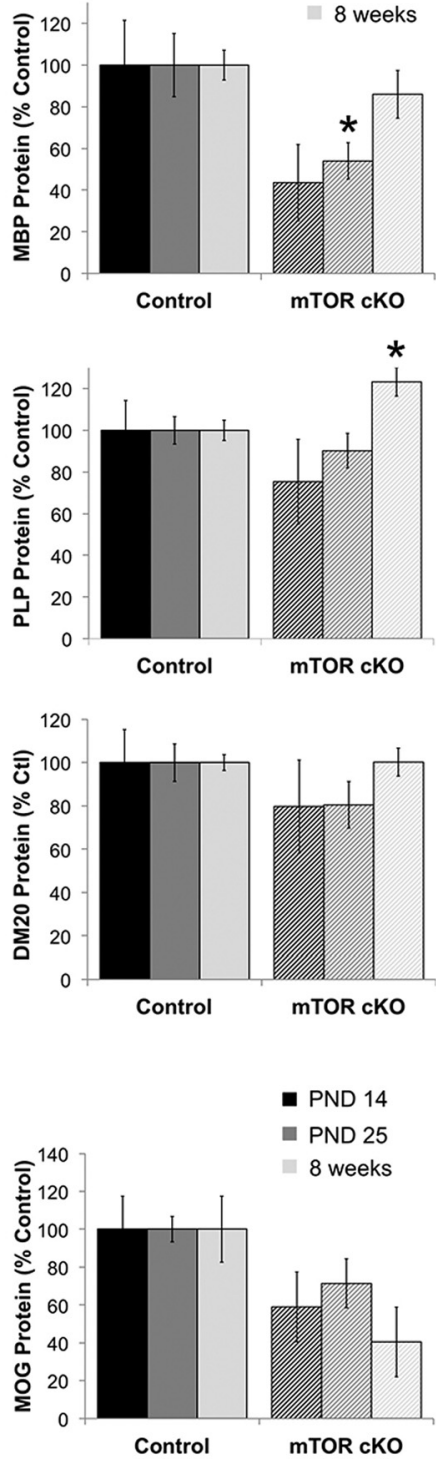

- PND 14

- PND 25

I 8 weeks

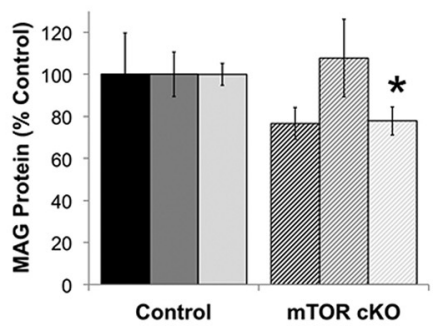

Figure 8. Myelin protein and mRNA expression in the cortex of $m T O R$ cKO. mRNA $(\boldsymbol{A}, \boldsymbol{C}, \boldsymbol{E}, \boldsymbol{G})$ and protein $(\boldsymbol{B}, \boldsymbol{D}, \boldsymbol{F}, \boldsymbol{H})$ expression was determined for MBP $(\boldsymbol{A}, \boldsymbol{B}), \operatorname{PLP} / \mathrm{DM} 20(\boldsymbol{C}, \boldsymbol{D}), \operatorname{MOG}(\boldsymbol{E}, \boldsymbol{F})$, and $\operatorname{MAG}(\mathbf{G}, \boldsymbol{H})$ in isolated cortex of control and mTOR CKO mice at PND14, PND25, and 8 weeks. Representative blots at each time point are shown for protein expression. mRNA analyses were performed on $n=6 /$ group from at least two independent litters. Protein analyses were performed on $n=9 /$ group from at least two independent litters. All quantifications are expressed as percentage control $\pm \mathrm{SE} .{ }^{*} p \leq 0.05$

elin to compensate for the reduction in total number of mature cells.

The effects of the mTOR cKO were distinct and less severe in the brain than in the spinal cord. However, one consistent effect across the CNS was the abnormal expression of myelin proteins in the mTOR cKO. Like the spinal cord, the expression of myelin proteins in cortex and cerebellum was reduced during development, but to a lesser degree. The expression of myelin proteins in the adult remained abnormal, with a significant increase in PLP and a decrease in MOG. However, the structure of the myelin in 


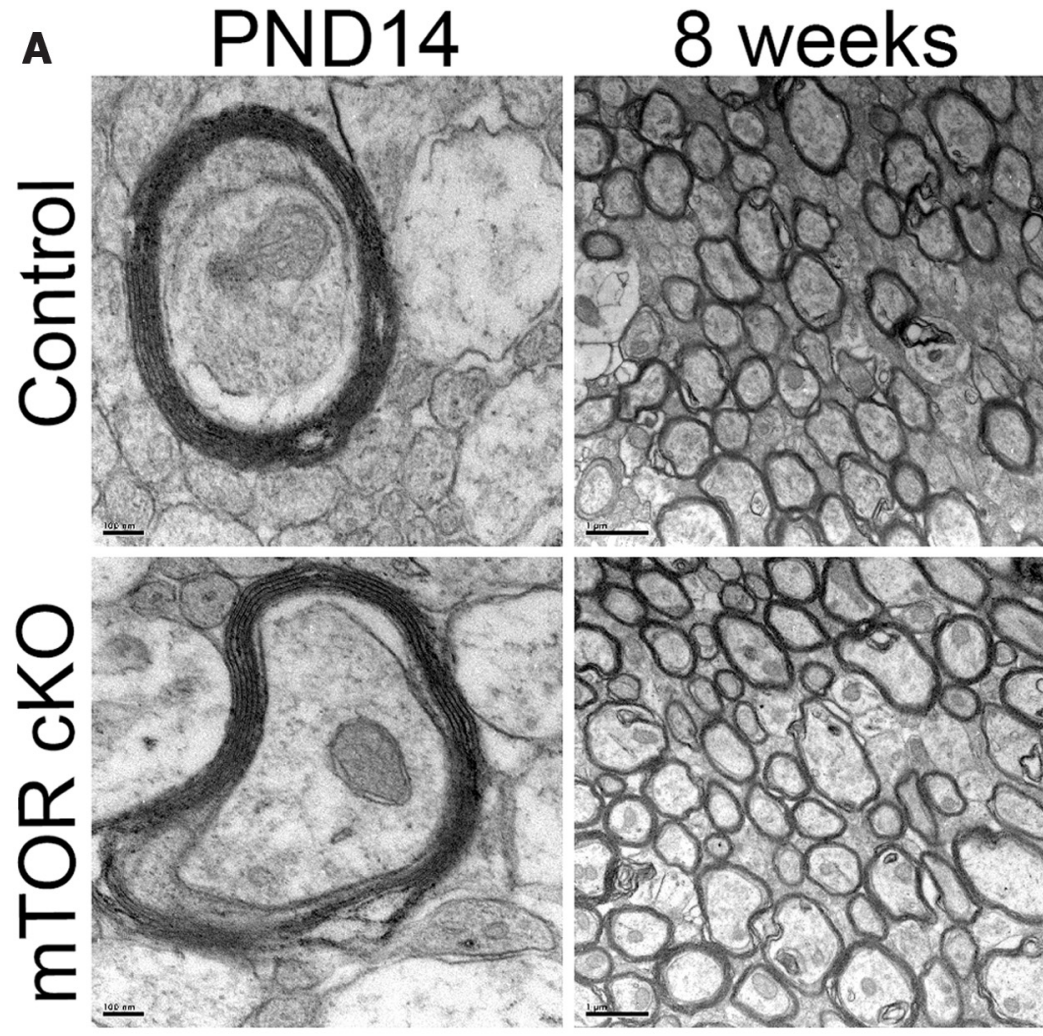

B
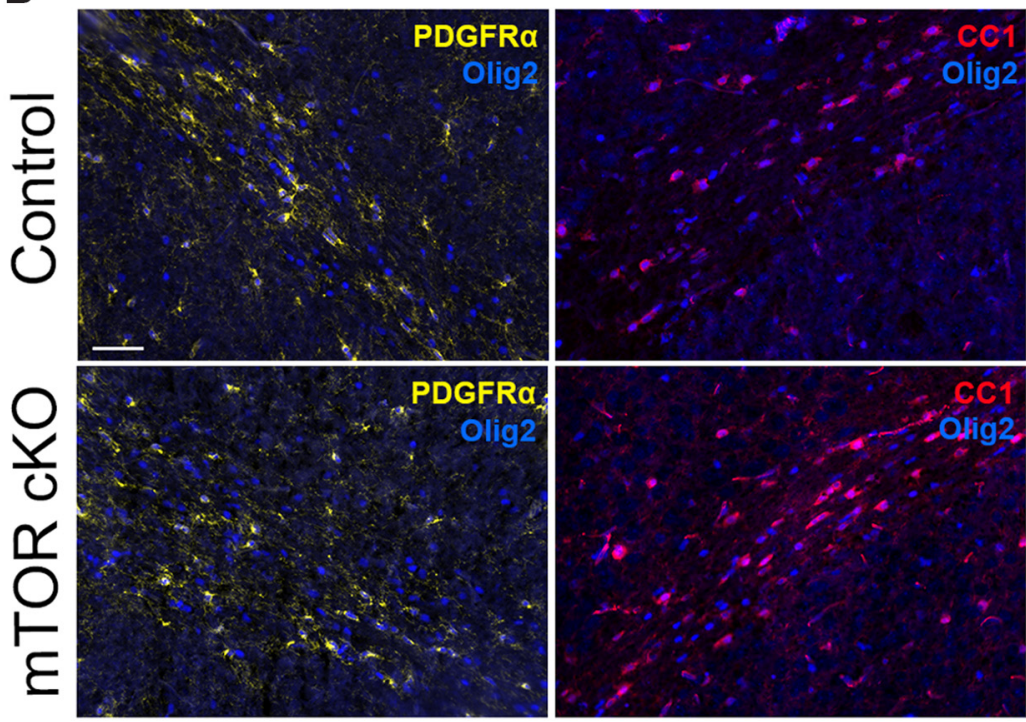

C

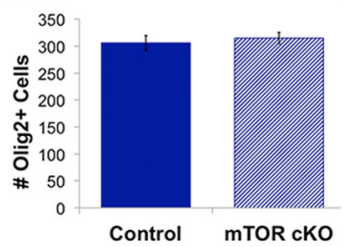

D

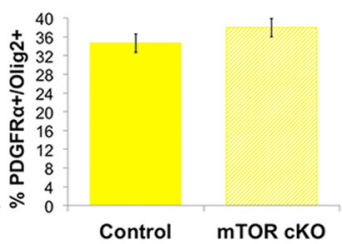

E

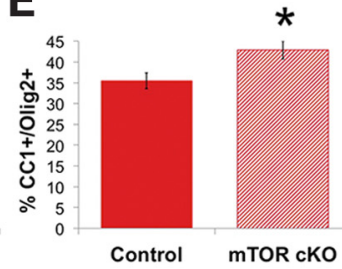

Figure 9. Differentiation and myelination in the brain of the mTOR CKO. $\boldsymbol{A}$, Electron micrograph images: at PND14 (Scale bar, $100 \mathrm{~nm}$ ) and at 8 weeks (Scale bar, $1 \mu \mathrm{m}$ ). $\boldsymbol{B}$, Representative images of PDGFR $\propto$ (yellow)/0lig2 (blue; nuclear) and CC1 (red)/0lig2 (blue; nuclear) immunofluorescence to identify early and late progenitors in the corpus callosum at PND14. Scale bar, $10 \mu \mathrm{m}$. $\boldsymbol{C}-\boldsymbol{E}$, Quantification of total Olig2 ${ }^{+}$cells $(\boldsymbol{C})$, percentage PDGFR $\propto^{+} /$Olig2 $^{+}$cells $(\boldsymbol{D})$, and percentage $\mathrm{CC} 1{ }^{+} / 0$ lig2 ${ }^{+}$cells $(\boldsymbol{E}) .{ }^{*} p \leq 0.05$.

the corpus callosum was not impaired, suggesting that mTOR either has a different role in myelination in the brain or that there are compensatory mechanisms in the brain for myelination that do not exist in the spinal cord.

The number of $\mathrm{CC}^{+}$oligodendrocytes in the brain is elevated at PND14 and reduced in the spinal cord at PND14 and 8 weeks. The mechanism for this difference is unclear; however, we believe that mTOR is regulating oligodendrocyte differentiation in the same manner in both regions, and it is either the inherent characteristics of the cells in each region or a difference in the amount of compensatory or redundant mechanisms in the brain that allows for its ability to have normal myelin.

The increase in $\mathrm{CC}^{+}$cells in the mTOR cKO corpus callosum may provide an explanation for the lack of an effect of the mTOR cKO on myelination in this region. Multiple intracellular signaling pathways regulate oligodendrocyte differentiation and myelination, including MAP kinases and PI3K/Akt/ mTOR. In vitro studies initially suggested a role for ERK signaling in oligodendrocyte differentiation (FyffeMaricich et al., 2011; Guardiola-Diaz et al., 2012). In contrast, a lack of both ERK1/2 in the brain in vivo resulted in reduced myelin thickness and a delay in myelin protein expression, but oligodendrocyte differentiation and the initiation of myelination were unaffected (Ishii et al., 2012). It is likely that ERK signaling and mTOR signaling coordinate phases of oligodendrocyte differentiation and developmental myelination, with at least some ability to compensate for each other, depending on the CNS region. This could account for the normal structure of myelin in the mTOR cKO brain despite the abnormal protein expression as well as the overcompensation observed in the number of mature oligodendrocytes in the corpus callosum with loss of mTOR.

Regional variability in the origins of oligodendrocytes in the spinal cord and the brain is well documented and could account for the regional differences we observe in the phenotype of the mTOR cKO. OPCs in the brain can be derived from three different sources, the medial ganglionic eminence and the lateral or caudal ganglionic eminences, two ventral sources, or within the postnatal cortex itself, a dorsal source (Kessaris et al., 2006). Whereas OPCs from all three regions are capable of populating and myelinating the 
brain, the dorsal source predominates in the adult brain. In contrast, whereas ventral and dorsal sources produce OPCs in the spinal cord, the ventral sources predominate in the adult. It remains to be determined whether the different populations of oligodendrocytes in the brain and spinal cord rely on the same extracellular and intracellular pathways for their development. In the spinal cord, there is evidence for different receptivity to PDGF in the ventral and dorsal populations of OPCs (Fruttiger et al., 1999). It is possible that the dorsal-derived OPCs in the brain depend less on mTOR signaling for their development than the ventral-derived OPCs in the spinal cord.

The exact mechanisms for how mTOR regulates oligodendrocyte differentiation, myelin protein expression, and myelination remain to be determined. The W.B.M. laboratory has recently investigated the role of each mTOR complex in the CNS by creating oligodendrocyte specific knock-outs of raptor and rictor (the integral components of mTORC1 and mTORC2, respectively) (Bercury et al. 2014). The loss of raptor or rictor resulted in impaired myelin protein expression during development. Loss of raptor had a more dramatic effect on myelination and oligodendrocyte differentiation than the loss of rictor. Like the mTOR $\mathrm{cKO}$, the effects on oligodendrocyte differentiation and myelination were more pronounced in the spinal cords of the raptor and rictor cKOs, and the changes in myelin protein expression varied by region. However, the most consistently effected protein across all regions was MBP, similar to what we found in the mTOR cKO at PND25. This suggests that the regulation of MBP by mTOR is through mTORC1. Moreover, these data further support the hypothesis that the distinct phenotypes observed in the mTOR and raptor cKOs in spinal cord and brain are the result of true regional differences and not a temporal effect of the gene deletion.

Overall, the phenotype of the raptor $\mathrm{cKO}$ most closely resembled the mTOR cKO, suggesting that the mTORC1 complex is more responsible for the effects seen in the mTOR cKO. One major difference in the phenotypes of these two cKOs is the dysmyelination observed in the raptor cKO but not in the mTOR $\mathrm{cKO}$. Thus, the presence of rictor/mTORC2 in the raptor $\mathrm{cKO}$ may actually accentuate the raptor $\mathrm{CKO}$ phenotype in some aspects. It is also the case that some deficits in myelin protein expression appeared more dramatic with loss of either raptor or rictor than for loss of mTOR in oligodendrocytes. This raises the possibility that raptor and/or rictor can function at least partially in the absence of mTOR in oligodendroglia, as has been demonstrated in other cell types. For example, raptor can complex with transcription factors in muscle to regulate mitochondrial gene transcription (Cunningham et al., 2007), and rictor can interact with integrin-linked kinase independent of mTOR to stimulate phosphorylation of Akt at Ser473 (McDonald et al., 2008). Finally, the regional variability observed in all three knock-out models furthers the hypothesis that multiple pathways regulate developmental myelination in the CNS. In particular, compensatory mechanisms seem more effective in the cortex than in the spinal cord. Whether this is the result of a different population of OPCs or the actions of another signaling pathway remains to be determined. It is perhaps most striking that all three cKOs in the mTOR pathway (mTOR, raptor, and rictor) have deficits in oligodendrocyte differentiation, a phenotype not observed in the ERK1/2 models. Further work into the mechanisms of mTORmediated oligodendrocyte differentiation and myelination and actions of the two mTOR signaling complexes in vivo may elucidate essential functions for each molecule, how the two complexes cross-regulate each other, and how other pathways function in CNS myelination.

\section{References}

Baumann N, Pham-Dinh D (2001) Biology of oligodendrocyte and myelin in the mammalian central nervous system. Physiol Rev 81:871-927. Medline

Bercury KK, Dai J, Sachs HH, Ahrendsen JT, Wood TL, Macklin WB (2014) Conditional ablation of Raptor or Rictor has differential impact on oligodendrocyte differentiation and CNS myelination. J Neurosci 34: $4466-4480$.

Biffiger K, Bartsch S, Montag D, Aguzzi A, Schachner M, Bartsch U (2000) Severe hypomyelination of the murine CNS in the absence of myelinassociated glycoprotein and fyn tyrosine kinase. J Neurosci 20:74307437. Medline

Carr TD, DiGiovanni J, Lynch CJ, Shantz LM (2012) Inhibition of mTOR suppresses UVB-induced keratinocyte proliferation and survival. Cancer Prev Res (Phila) 5:1394-1404. CrossRef Medline

Cunningham JT, Rodgers JT, Arlow DH, Vazquez F, Mootha VK, Puigserver P (2007) mTOR controls mitochondrial oxidative function through a YY1-PGC-1alpha transcriptional complex. Nature 450: 736-740. CrossRef Medline

Fancy SP, Harrington EP, Yuen TJ, Silbereis JC, Zhao C, Baranzini SE, Bruce CC, Otero JJ, Huang EJ, Nusse R, Franklin RJ, Rowitch DH (2011) Axin2 as regulatory and therapeutic target in newborn brain injury and remyelination. Nat Neurosci 14:1009-1016. CrossRef Medline

Flores AI, Narayanan SP, Morse EN, Shick HE, Yin X, Kidd G, Avila RL, Kirschner DA, Macklin WB (2008) Constitutively active Akt induces enhanced myelination in the CNS. J Neurosci 28:7174-7183. CrossRef Medline

Foran DR, Peterson AC (1992) Myelin acquisition in the central nervous system of the mouse revealed by an MBP-Lac Z transgene. J Neurosci 12:4890-4897. Medline

Franklin RJ (2002) Why does remyelination fail in multiple sclerosis? Nat Rev Neurosci 3:705-714. CrossRef Medline

Franklin KB, Paxinos G (2008) The mouse brain stereotaxis coordinates, third edition. San Diego: Elsevier.

Fruttiger M, Karlsson L, Hall AC, Abramsson A, Calver AR, Boström H, Willetts K, Bertold CH, Heath JK, Betsholtz C, Richardson WD (1999) Defective oligodendrocyte development and severe hypomyelination in PDGF-A knockout mice. Development 126:457-467. Medline

Furusho M, Dupree JL, Nave KA, Bansal R (2012) Fibroblast growth factor receptor signaling in oligodendrocytes regulates myelin sheath thickness. J Neurosci 32:6631-6641. CrossRef Medline

Fyffe-Maricich SL, Karlo JC, Landreth GE, Miller RH (2011) The ERK2 mitogen-activated protein kinase regulates the timing of oligodendrocyte differentiation. J Neurosci 31:843-850. CrossRef Medline

Goebbels S, Oltrogge JH, Kemper R, Heilmann I, Bormuth I, Wolfer S, Wichert SP, Möbius W, Liu X, Lappe-Siefke C, Rossner MJ, Groszer M, Suter U, Frahm J, Boretius S, Nave KA (2010) Elevated phosphatidylinositol 3,4,5-trisphosphate in glia triggers cell-autonomous membrane wrapping and myelination. J Neurosci 30:8953-8964. CrossRef Medline

Guardiola-Diaz HM, Ishii A, Bansal R (2012) Erk1/2 MAPK and mTOR signaling sequentially regulates progression through distinct stages of oligodendrocyte differentiation. Glia 60:476-486. CrossRef Medline

Harrington EP, Zhao C, Fancy SP, Kaing S, Franklin RJ, Rowitch DH (2010) Oligodendrocyte PTEN is required for myelin and axonal integrity, not remyelination. Ann Neurol 68:703-716. CrossRef Medline

He Y, Dupree J, Wang J, Sandoval J, Li J, Liu H, Shi Y, Nave KA, CasacciaBonnefil P (2007) The transcription factor Yin Yang 1 is essential for oligodendrocyte progenitor differentiation. Neuron 55:217-230. CrossRef Medline

Ishii A, Fyffe-Maricich SL, Furusho M, Miller RH, Bansal R (2012) ERK1/ ERK2 MAPK signaling is required to increase myelin thickness independent of oligodendrocyte differentiation and initiation of myelination. J Neurosci 32:8855-8864. CrossRef Medline

Kessaris N, Fogarty M, Iannarelli P, Grist M, Wegner M, Richardson WD (2006) Competing waves of oligodendrocytes in the forebrain and postnatal elimination of an embryonic lineage. Nat Neurosci 9:173-179. CrossRef Medline

Lang CH, Frost RA, Bronson SK, Lynch CJ, Vary TC (2010a) Skeletal muscle protein balance in mTOR heterozygous mice in response to inflammation and leucine. Am J Physiol Endocrinol Metab 298:E1283-E1294. CrossRef Medline

Lang SA, Hackl C, Moser C, Fichtner-Feigl S, Koehl GE, Schlitt HJ, Geissler 
EK, Stoeltzing O (2010b) Implication of RICTOR in the mTOR inhibitor-mediated induction of insulin-like growth factor-I receptor (IGF-IR) and human epidermal growth factor receptor-2 (Her2) expression in gastrointestinal cancer cells. Biochim Biophys Acta 1803:435-442. CrossRef Medline

Lappe-Siefke C, Goebbels S, Gravel M, Nicksch E, Lee J, Braun PE, Griffiths IR, Nave KA (2003) Disruption of Cnp1 uncouples oligodendroglial functions in axonal support and myelination. Nat Genet 33:366-374. CrossRef Medline

Lytle JM, Chittajallu R, Wrathall JR, Gallo V (2009) NG2 cell response in the CNP-EGFP mouse after contusive spinal cord injury. Glia 57:270-285. CrossRef Medline

McDonald PC, Oloumi A, Mills J, Dobreva I, Maidan M, Gray V, Wederell ED, Bally MB, Foster LJ, Dedhar S (2008) Rictor and integrin-linked kinase interact and regulate Akt phosphorylation and cancer cell survival. Cancer Res 68:1618-1624. CrossRef Medline

Narayanan SP, Flores AI, Wang F, Macklin WB (2009) Akt signals through the mammalian target of rapamycin pathway to regulate CNS myelination. J Neurosci 29:6860-6870. CrossRef Medline

Richardson WD, Smith HK, Sun T, Pringle NP, Hall A, Woodruff R (2000) Oligodendrocyte lineage and the motor neuron connection. Glia 29:136142. CrossRef Medline

Sherman DL, Krols M, Wu LM, Grove M, Nave KA, Gangloff YG, Brophy PJ (2012) Arrest of myelination and reduced axon growth when Schwann cells lack mTOR. J Neurosci 32:1817-1825. CrossRef Medline

Spassky N, Olivier C, Perez-Villegas E, Goujet-Zalc C, Martinez S, Thomas J,
Zalc B (2000) Single or multiple oligodendroglial lineages: a controversy. Glia 29:143-148. CrossRef Medline

Tyler WA, Gangoli N, Gokina P, Kim HA, Covey M, Levison SW, Wood TL (2009) Activation of the mammalian target of rapamycin (mTOR) is essential for oligodendrocyte differentiation. J Neurosci 29:6367-6378. CrossRef Medline

Tyler WA, Jain MR, Cifelli SE, Li Q, Ku L, Feng Y, Li H, Wood TL (2011) Proteomic identification of novel targets regulated by the mammalian target of rapamycin pathway during oligodendrocyte differentiation. Glia 59:1754-1769. CrossRef Medline

Wong AW, Xiao J, Kemper D, Kilpatrick TJ, Murray SS (2013) Oligodendroglial expression of TrkB independently regulates myelination and progenitor cell proliferation. J Neurosci 33:4947-4957. CrossRef Medline

Wood TL, Bercury KK, Cifelli SE, Mursch LE, Min J, Dai J, Macklin WB (2013) mTOR: a link from the extracellular milieu to transcriptional regulation of oligodendrocyte development. ASN Neuro 5:e00108. CrossRef Medline

Ye P, Li L, Lund PK, D’Ercole AJ (2002) Deficient expression of insulin receptor substrate-1 (IRS-1) fails to block insulin-like growth factor-I (IGF-I) stimulation of brain growth and myelination. Brain Res Dev Brain Res 136:111-121. CrossRef Medline

Zeger M, Popken G, Zhang J, Xuan S, Lu QR, Schwab MH, Nave KA, Rowitch D, D'Ercole AJ, Ye P (2007) Insulin-like growth factor type 1 receptor signaling in the cells of oligodendrocyte lineage is required for normal in vivo oligodendrocyte development and myelination. Glia 55:400-411. CrossRef Medline 